\title{
Dynamic risk spillovers between gold, oil prices and conventional, sustainability and Islamic equity aggregates and sectors with portfolio implications
}

\author{
Walid Mensi a,b Shawkat Hammoudeh ${ }^{\text {c,d }}$, Idries Mohammad Wanas Al-Jarrah ${ }^{\mathrm{e}}$, \\ Ahmet Sensoy ${ }^{f}$, Sang Hoon Kang ${ }^{g, *}$ \\ a Department of Finance and Accounting, University of Tunis El Manar, Tunis, Tunisia \\ ${ }^{\mathrm{b}}$ Department of Economics and Finance, College of Economics and Political Science, Sultan Qaboos University, Muscat, Oman \\ c Lebow College of Business, Drexel University, Philadelphia, United States \\ d Energy and Sustainable Development (ESD), Montpellier Business School, Montpellier, France \\ e College of Business and Economics, Qatar University, Qatar \\ ${ }^{\mathrm{f}}$ Faculty of Business Administration, Bilkent University, Ankara 06800, Turkey \\ ${ }^{g}$ Department of Business Administration, Pusan National University, Busan, Republic of Korea
}

\section{A R T I C L E I N F O}

\section{Article history:}

Received 15 January 2017

Received in revised form 13 July 2017

Accepted 25 August 2017

Available online 14 September 2017

\section{JEL classification: \\ G14}

G15

\section{Keywords:}

Commodity markets

Sustainability and conventional equity indexes

Islamic equity markets

Spillovers

Downside risk reductions

\begin{abstract}
A B S T R A C T
This paper investigates the time-varying equicorrelations and risk spillovers between crude oil, gold and the Dow Jones conventional, sustainability and Islamic stock index aggregates and 10 associated disaggregated Islamic sector stock indexes (basic materials, consumer services, consumer goods, energy, financials, health care, technology, industrials, telecommunications and utilities), using the multivariate DECO-FIAPARCH model and the spillover index of Diebold and Yilmaz (2012). We also conduct a risk management analysis at the sector level for commodity-Islamic stock sector index portfolios, using different risk exposure measures. For comparison purposes, we add the aggregate conventional Dow Jones global index and the Dow Jones sustainability world index. The results show evidence of time-varying risk spillovers between these markets. Moreover, there are increases in the correlations among the markets in the aftermath of the 2008-2009 GFC. Further, the oil, gold, energy, financial, technology and telecommunications sectors are net receivers of risk spillovers, while the sustainability and conventional aggregate DJIM indexes as well as the remaining Islamic stock sectors are net contributors of risk spillovers. Finally, we provide evidence that gold offers better portfolio diversification benefits and downside risk reductions than oil.
\end{abstract}

(c) 2017 Elsevier B.V. All rights reserved.

\section{Introduction}

The global financial system has increasingly become more complex due to ongoing structural changes including technological improvements and innovative financial products, which have affected the world's economy and the global financial architecture. In particular, the last two decades have been an era of global financial integration connecting several asset classes together and leading to amplified correlations between them. In the eyes of asset managers and policymakers, this complex situation is a tough challenge that requires hedging through diversification and other protection measures to provide financial stability.

Consecutively, the Islamic finance industry has become an alternative business model to its conventional counterparts in the world of financial

\footnotetext{
* Corresponding author.

E-mail addresses: walid.mensi@fsegt.rnu.tn (W. Mensi), hammousm@drexel.edu (S. Hammoudeh), idries@qu.edu.qa (I.M.W. Al-Jarrah), ahmet.sensoy@bilkent.edu.tr (A. Sensoy), sanghoonkang@pusan.ac.kr (S.H. Kang).
}

intermediation and a promise for more diversification opportunities and financial stability. Over the past two decades, the Shariah-compliant industry has experienced significant growth due to growing interest from the Western world and faith-oriented investors, particularly after the 2008 financial crisis, and as a result of accumulation of oil wealth in faith-supporting countries and a strong participation from faithful investors, combined with a keen willingness of regulators to give more room for this industry. Current estimates of the size of the global Islamic finance assets under management range between USD 1.7 and 2.1 trillion in 2016 and the Islamic Finance industry is expected to grow further in the future.

The Islamic-listed stock securities, which are part of the Islamic finance industry, are a subset of the broader global Islamic securities universe that meets defined screening criteria to assess their compliance with the Shariah principles, and hence their suitability to be considered as Shariah compliant securities. Therefore, the volatility and pricing movements in global stock markets also have an effect on the Shariah-compliant securities (IFSI Stability Report, 2016). This fact leads one to search for more viable alternative asset classes to foster 
the diversification sought by global investors who prefer to include Islamic securities in their investments. Commodities, gold and oil, in particular, are the very first candidates that come to mind in this process. From a traditional perspective, the commodity and equity markets (whether Shariacompliant or not) are normally inversely related, and therefore commodities are considered to be good portfolio diversifiers (Kang, 2012). For example, gold has traditionally been used as a hedge against inflation and crises. As the US dollar weakens and inflation creeps up, investors would prefer to invest in gold in order to take advantage of potentially higher inflation (Baur and McDermott, 2010). Similarly, in times of substantial price decreases in the stock market, not only gold but also oil may tend to increase in price (Dorsman et al., 2012) ${ }^{1}$ If goal is to reduce the risk of Islamic equity portfolios, the literature has not paid much attention to combinations that include gold, oil and Islamic equity indexes.

Examples of those studies that have paid some attention to this asset mixture include Abdullah et al. (2016), Mensi et al. (2015a, 2015b), and Nagayev et al. (2016). However, the problem with these examples is that the first two studies focus on a very limited set of countries (namely Singapore, Malaysia, Philippines and Saudi Arabia), while the latter two consider only a global Islamic equity market index. This shows that a much deeper research is required to analyze the nexus between the most popular commodities, gold and oil, and Islamic equity markets at the aggregate and sector levels. In addition, the obvious missing point is that when we consider Islamic equities at the aggregate level, we miss the opportunity of diversification at the sectoral level. To the best of our knowledge, this study is one of the first that analyzes the interactions between vital commodities (gold and oil) and the Islamic equities at the sectoral level, employs downside risk reduction measures and investigate portfolio diversification benefits. We also consider the aggregate conventional Dow Jones global index (W1DOW) and Dow Jones sustainability world index (W1SGI) for comparison purposes. ${ }^{2}$ It is clear that such an analysis would be invaluable in risk management and portfolio construction. Therefore, in this study, we focus on the relationship between gold and oil, and both the Dow Jones aggregate conventional, sustainability, Islamic equity indexes as well as the 10 disaggregate Islamic equity sectors at a global scale. This comprehensive analysis should make this study the first in the literature in this regard.

In particular, using daily data covering almost 20 years, we first implement the multivariate dynamic equicorrelation-fractionally integrated asymmetric power autoregressive conditional heteroskedasticity (DECO-FIAPARCH) model to measure dynamic correlations among conventional stock index, sustainability stock index, the aggregate Islamic stock market, their 10 Islamic sectors and the two commodity markets (oil and gold). Then, we apply the generalized spillover index of Diebold and Yilmaz $(2012,2014,2016)$ to examine the directional spillovers and net spillovers across the commodities and the Islamic sector indices. Further, we use the approach of Kroner and Ng (1998) and variance-minimizing hedging strategies to find the time-varying optimal portfolio weights, using the commodities and the Islamic sectoral indexes together to investigate the usefulness of the gold and oil markets for risk management in the Islamic sectoral stock markets. Finally, we estimate the corresponding Value-at-Risk (VaR),

\footnotetext{
${ }^{1}$ However, with the easy access of commodities through financialization in the recent years, commodity prices are not only determined by their primary supply and demand anymore but also by this process. Therefore, the traditional interpretations of the relation between equities and commodities have been questioned lately (Silvennoinen and Thorp, 2013).

2 The Dow Jones Sustainability Indices are a family of best-in-class benchmarks for investors who have recognized that sustainable business practices are critical to generating long-term shareholder values and who wish to reflect their sustainability convictions in their investment portfolios. The family was launched in 1999 as the first global sustainability benchmark and tracks the stock performance of the world's leading companies in terms of economic, environmental and social criteria. For further information the reader can refer to the following link http://webcache.googleusercontent.com/search?q= cache:http://www.sustainability-indices.com/index-family-overview/djsi-familyoverview/
}

Semivariance (SV) and the Regret (Re) measures to help guide portfolio managers planning to use Islamic equities in designing their strategies.

Our contributions to the literature are three-fold. First, as indicated above, this is the first study that investigates the diversification benefits and the interactions between commodities such as gold and oil, and the Islamic equities at the sectoral level in a global environment. In fact, the aggregate DJIM is sector oriented as the Shariah-compliant firms are heavily concentrated in some sectors like basic materials, technology and industrials. These dissimilarities motivate us to address these interactions and diversification with Islamic indexes. Second, the study covers almost 20 years of daily data which includes crucial events such as the 2001 dotcom bubble, the 2008 global financial crisis (GFC) and the 2012 European sovereign debt crisis (ESDC). Such events allow us to examine the dynamics of equicorrelations, volatility spillovers, optimal portfolio structures and hedging strategies during crisis periods. Third, we use the state of the art methodologies such as the DECO-FIAPARCH, the generalized spillover index of Diebold and the Yilmaz (DY) (2012), optimal portfolio weighting by Kroner and $\mathrm{Ng}$ (1998) in our analysis. Further, the findings are strengthened by various risk effectiveness measures.

Our results show a time-varying equicorrelations for the commodity and Islamic stock markets. Furthermore, the spillover index analysis reveals that gold has a lower impact on the Islamic stock markets than the crude oil market, and the latter is a greater receiver of shocks than gold. The results indicate that oil and gold are net receivers of volatility, while surprisingly the aggregate Islamic stock (DJIM) index is a net contributor to volatility spillovers. Furthermore, the recent GFC and the ESDC intensify the total volatility spillovers across the considered markets. Among the 10 Islamic sectors, the consumer goods and the industrials are the highest net volatility contributors, while the finance, technology and telecommunication sectors are the lowest contributors of volatility spillovers, and in fact they are net receivers with the finance sector being the most vulnerable. Further, the risk spillovers between the Islamic stock sectoral markets are globally weak. We find that the optimally weighted portfolio offers both the best risk reductions and the largest downside risk reduction for all oil-Islamic stock sector pairs, the gold-DJIM, gold-Islamic consumer services, the gold-Islamic consumer goods, the gold-Islamic health care, and the gold-Islamic industrials. For the rest of the gold-Islamic sector stock pairs, the hedged portfolio provides the best risk reductions. Finally, gold offers better diversification benefits, risk reductions and the largest downside risk reductions than oil.

The remainder of this study is organized as follows. Section 2 presents the literature review. Section 3 discusses the methodology. Section 4 describes the data and conducts some preliminary analysis. Section 5 reports and discusses the empirical results. Section 6 provides concluding remarks.

\section{Literature review}

The early empirical literature has focused on the relative performance of the Islamic finance industry in comparison to its conventional counterparts (e.g., Hayat and Kraussl, 2011; Milly and Sultan, 2012; Beck et al., 2013; Jawadi et al., 2014; Al-Khazali et al., 2014). However, with the occurrence of the recent global financial crisis and the following eurozone debt crisis, researchers and policy makers redirected their attention to the potential risk management applications of Islamic financial assets. The major part of those recent studies focuses on analyzing spillovers between Islamic and conventional assets, and shows how to use those assets in portfolio constructions. The earlier studies in the literature consider combining conventional equities with their Islamic counterparts. For example, in a theoretical framework, Umar (2017) considers two types of stock investors: faith-based and conventional-based. The faith-based investors invest in Shariah complaint equities only and exclude conventional equities from the asset menu. On the other hand, the conventional investors' asset 

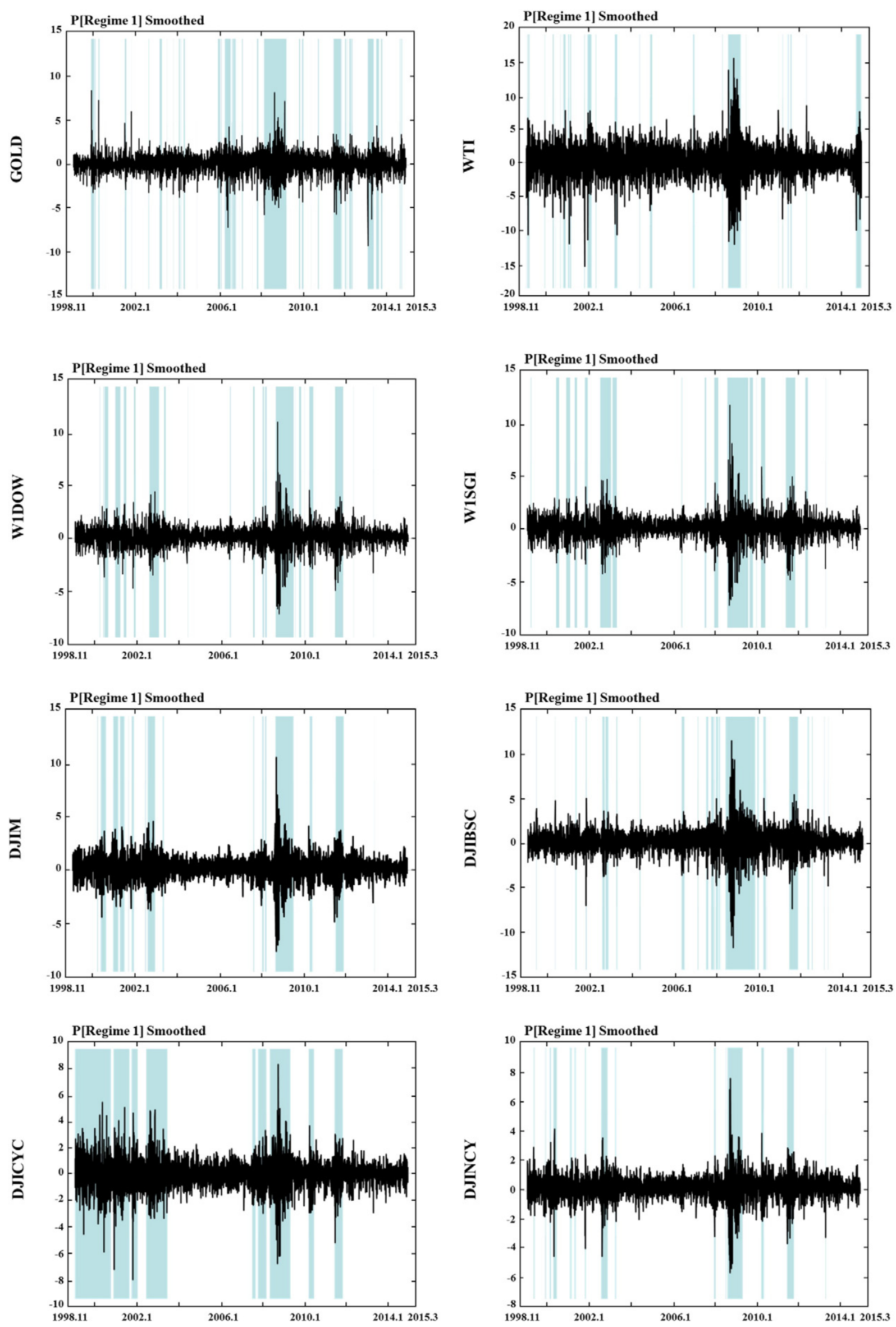

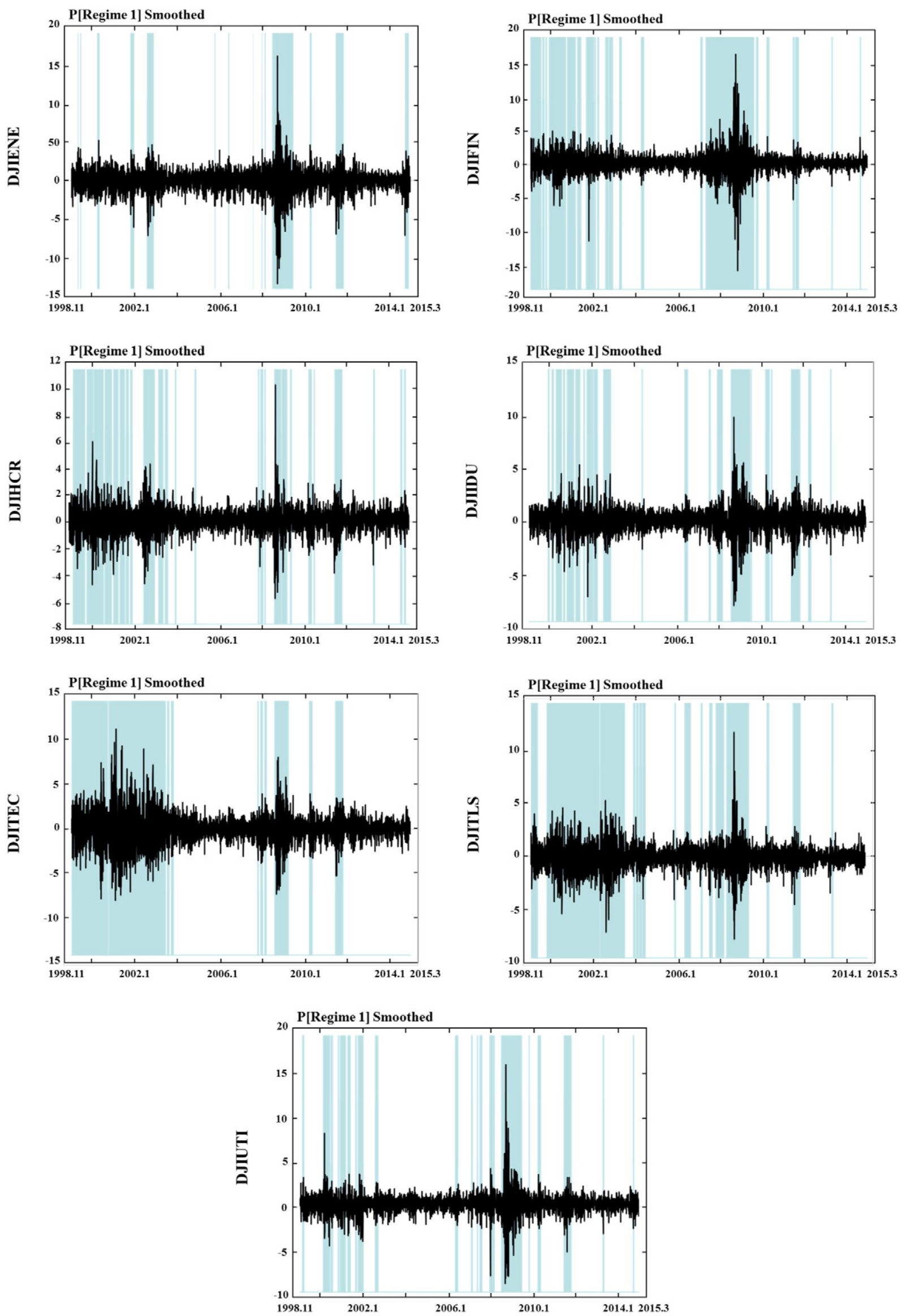

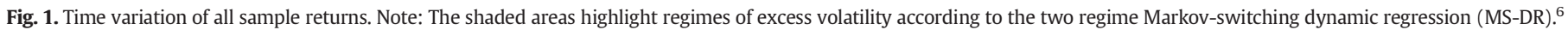
${ }^{6}$ 口For further details on the MS-DR model, see Hamilton (1988) and Hamilton and Susmel (1994). The MS-DR method is conducted by Ox metrics. 
Table 1

Descriptive statistics of gold, WTI oil, Dow Jones sustainability world index, conventional Dow Jones global index, DJIM index and the Islamic sector stock index returns.

\begin{tabular}{|c|c|c|c|c|c|c|c|c|c|c|c|c|c|}
\hline & Mean & Max. & Min. & Std. dev. & Skewness & Kurtosis & $\mathrm{JB}$ & $\mathrm{Q}(30)$ & $Q^{2}(30)$ & $\mathrm{ADF}$ & PP & KPSS & ARCH-LM(10) \\
\hline GOLD & 0.0345 & 8.8303 & -9.8105 & 1.1784 & -0.143 & 9.045 & $6206^{* * *}$ & $51.76^{* * *}$ & $713.8^{* * *}$ & $-63.62^{* * * *}$ & $-63.62^{* * *}$ & 0.1589 & $20.63^{* * *}$ \\
\hline WTI & 0.0327 & 16.407 & -16.544 & 2.3971 & -0.255 & 7.344 & $3242^{* * *}$ & $56.09^{* * *}$ & $3289^{* * *}$ & $-66.02^{* * *}$ & $-66.08^{* * *}$ & 0.2827 & $57.81^{* * * *}$ \\
\hline W1D0W & 0.0153 & 11.470 & -7.6568 & 1.0536 & -0.280 & 15.448 & $15,177^{* * *}$ & $100.7^{* * *}$ & $7744^{* * *}$ & $-56.26^{* * *}$ & $-55.96^{* * *}$ & 0.0763 & $162.92^{* * *}$ \\
\hline W1SGI & 0.0085 & 12.221 & -7.7746 & 1.1699 & -0.072 & 11.50 & $12,264^{* * *}$ & $119.9^{* * *}$ & $5880^{* * *}$ & $-57.99^{* * *}$ & $-57.74^{* * *}$ & 0.0669 & $112.83^{* * *}$ \\
\hline DJIM & 0.0169 & 10.984 & -8.1854 & 1.0993 & -0.283 & 10.67 & $10,041^{* * * *}$ & $47.83^{* * * *}$ & $6345^{* * *}$ & $-41.91^{* * *}$ & $-70.21^{* * *}$ & 0.0900 & $182.84^{* * * *}$ \\
\hline DJIBSC & 0.0224 & 12.062 & -12.551 & 1.4338 & -0.546 & 12.62 & $15,887^{* * *}$ & $264.7^{* * *}$ & $8711^{* * *}$ & $-41.02^{* * *}$ & $-64.62^{* * *}$ & 0.0831 & $207.92^{* * *}$ \\
\hline DJICYC & 0.0269 & 8.7624 & -8.2846 & 1.1479 & -0.167 & 7.677 & $3725^{* * *}$ & $200.5^{* * *}$ & $2950^{* * * *}$ & $-43.57^{* * *}$ & $-73.36^{* * *}$ & 0.1106 & $71.678^{* * *}$ \\
\hline DJINCY & 0.0201 & 7.8587 & -6.1352 & 0.8502 & -0.325 & 10.96 & $10,812 .^{* * *}$ & $352.5^{* * *}$ & $4610^{* * *}$ & $-43.89^{* * *}$ & $-71.57^{* * *}$ & 0.1242 & $136.84^{* * *}$ \\
\hline DJIENE & 0.0191 & 16.879 & -13.905 & 1.5287 & -0.456 & 14.08 & $48,114^{* * * *}$ & $122.6^{* * *}$ & $7227^{* * *}$ & $-42.93^{\text {**** }}$ & $-73.14^{* * *}$ & 0.0814 & $201.95^{* * * *}$ \\
\hline DJIFIN & 0.0111 & 17.277 & -16.981 & 1.5741 & -0.023 & 20.18 & $50,026^{* * *}$ & $199.0^{* * *}$ & $6533^{* * * *}$ & $-43.86^{* * *}$ & $-1814^{* * *}$ & 0.0450 & $154.12^{* * *}$ \\
\hline DJIHCR & 0.0219 & 10.747 & -6.1933 & 0.9841 & -0.112 & 10.35 & $9178^{* * *}$ & $139.6^{* * *}$ & $3010^{* * *}$ & $-44.12^{* * *}$ & $-69.80^{* * *}$ & 0.2114 & $94.99^{* * *}$ \\
\hline DJIIDU & 0.0215 & 10.231 & -8.3919 & 1.1872 & -0.332 & 9.251 & $6695^{* * *}$ & $192.9^{* * * *}$ & $6136^{* * *}$ & $-40.64^{* * *}$ & $-66.94^{* * *}$ & 0.0876 & $153.9^{* * *}$ \\
\hline DJITEC & 0.0125 & 11.719 & -8.2984 & 1.6886 & 0.120 & 7.442 & 3353. .** $^{* *}$ & $60.74^{* * * *}$ & 4438. ${ }^{* * *}$ & $-43.19^{* * *}$ & $-73.84^{* * *}$ & 0.1316 & $87.41^{* * * *}$ \\
\hline DJITLS & 0.0069 & 12.426 & -8.0750 & 1.1992 & 0.088 & 9.457 & $7069^{* * *}$ & $106.1^{* * *}$ & $3949^{* * *}$ & $-43.59^{* * *}$ & $-70.37^{* * *}$ & 0.0826 & $106.8^{* * *}$ \\
\hline DJIUTI & 0.0024 & 16.509 & -9.3299 & 1.1455 & 0.097 & 24.30 & $76,931^{* * *}$ & $166.1^{* * *}$ & $4559^{* * *}$ & $-44.29^{* * *}$ & $-71.55^{* * *}$ & 0.1227 & $203.2^{* * *}$ \\
\hline
\end{tabular}

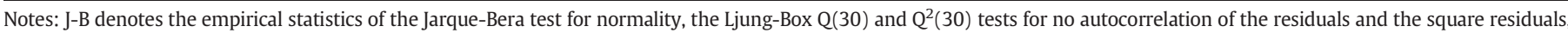

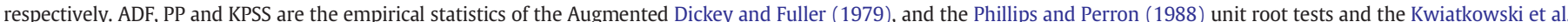

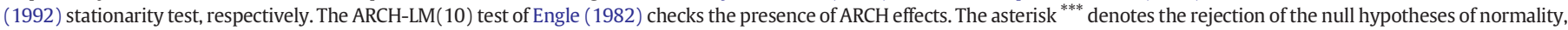
no autocorrelation, unit root, stationarity, and conditional homoscedasticity at the $1 \%$ significance level.

menu comprises both Islamic and conventional equities. Accordingly, the inclusion of Islamic equities in the asset menu of faith-based investors results in substantial welfare gains; and this result has been empirically verified by more recent studies (Hammoudeh et al., 2014; Rahim and Masih, 2016; Dewandaru et al., 2016; Charfeddine et al., 2016; Majdoub et al., 2016). ${ }^{3}$ Less attention has been given on combining Islamic equities and commodities in the literature. Among those few, Abdullah et al. (2016) find that the Philippine Islamic stock index is less correlated with crude oil in the short run (as evidenced by a continuous wavelet transform analysis) and that an investor holding crude oil can gain by including the Malaysian Islamic stock index in the portfolio (as evidenced by a dynamic conditional correlation analysis).

Mensi et al. (2015a) examine the time-varying linkages of the Saudi stock market with major commodity futures markets including WTI oil, gold, silver, wheat, corn and rice, using the bivariate DCC-FIAPARCH model with and without structural breaks. For mixed commoditystock portfolios, those authors find strong evidence of diversification benefits, hedging effectiveness and downside risk reductions. Using the MGARCH-DCC and wavelet coherence framework, Nagayev et al. (2016) reveal that the correlations between commodity markets and the Dow Jones Islamic market world index are time-varying and highly volatile throughout the January 1999-April 2015 period. A substantial and persistent increase is observed in the return correlations between commodities and Islamic equity at the onset of the 2008 GFC. However, the trends in the recent two years suggest that this association is heading toward its pre-crisis levels, offering again diversification benefits for Islamic equity holders. These benefits vary across different commodities in various time scales. Overall, gold, natural gas, soft commodities, grains and livestock are better portfolio diversifiers than oil and other metals. Mensi et al. (2015b) examine whether the Sharia-compliant stocks measured by the Dow Jones Islamic world emerging market index (DJIWEM) and gold can serve as a hedge and/or a safe-haven asset in the six GCC stock markets, by using a vine copula approach. The results show that GCC and global investors can realize both risk diversification benefits and downside risk reductions during tranquil and downturn periods by including gold or DJIWEM in their portfolios.

The problem with the abovementioned studies is that they all consider Islamic equities at the aggregate level, and therefore they miss the opportunities of examining diversification at the sectoral level. Indeed, among the whole literature, the studies that take into account the interactions of such sector indexes can be counted on the fingers of one hand. For example, Balcilar et al. (2015) assess the risk exposures of major Islamic sector indexes with respect to shocks in global conventional markets but without including refuge assets and find positive risk exposures of Islamic equity sectors with respect to developed market shocks. Those authors find that both the in- and out-of-sample results suggest that portfolios supplemented with positions in the Islamic equity sectors yield much improved risk-adjusted returns, thereby implying significant international diversification benefits. In particular, the Financials, Healthcare, Telecommunication and Utilities sectors are found to have greater significance in global diversification strategies due to their higher weights allocated in the optimal portfolios. A recent study by Mensi et al. (2016) takes a different perspective of Islamic sector investing from the one undertaken by Balcilar et al. (2015). Accordingly, Mensi et al. (2016) analyze the dynamic spillovers across 10 Dow Jones Islamic and conventional sector index pairs. Using four different MVGARCH-cDCC models, they find evidence of the claim that the conditional correlations for all the sector pairs (except those of the Telecommunication and Utilities sectors) increase after the onset of the global financial crisis, suggesting non-subsiding risks, contagion effects and gradual greater financial linkages. Accordingly, the Islamic sectors' risk exposure can be effectively hedged over time in diversified portfolios containing conventional sector stocks. ${ }^{4}$

However, to the best of our knowledge, there is no study that analyzes the interaction between commodities such as gold and oil, and the Islamic equities at the sectoral level as explained in the introduction section. The extensive literature reviewed above suggests that such an analysis would be invaluable in risk management, in particular for portfolio construction.

\section{Empirical method}

This section discusses the empirical methods used in this study. First, we present a multivariate DECO-FIAPARCH model, which measures the dynamic conditional correlations between the markets under consideration as explained earlier. Second, we present the spillover index of Diebold and Yilmaz (2012), which identifies the dynamics of directional volatility spillovers across the commodity and stock markets under consideration.

\footnotetext{
${ }^{3}$ Alternatively, some studies suggest that combining the conventional U.S. markets with emerging Islamic equity markets leads to improved portfolio performance (see Majdoub and Mansour, 2014; Saiti et al., 2014).
}

\footnotetext{
${ }^{4}$ Both results are indirectly supported by Yilmaz et al. (2015) and Sensoy (2016).
} 
Table 2

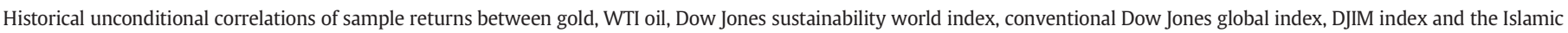
sector stock indices.

\begin{tabular}{|c|c|c|c|c|c|c|c|c|c|c|c|c|c|c|c|}
\hline & GOLD & WTI & W1D0W & W1SGI & DJIM & DJBSC & DJICYC & DJNCY & DJIENE & DJIFIN & DJIHCR & DJIIDU & DJITEC & DJITLS & DJIUTI \\
\hline GOLD & 1.0000 & & & & & & & & & & & & & & \\
\hline WTI & 0.2195 & 1.0000 & & & & & & & & & & & & & \\
\hline W1D0W & 0.1032 & 0.2681 & 1.0000 & & & & & & & & & & & & \\
\hline W1SGI & 0.1261 & 0.2614 & 0.9457 & 1.0000 & & & & & & & & & & & \\
\hline DJIM & 0.1118 & 0.2813 & 0.9758 & 0.9114 & 1.0000 & & & & & & & & & & \\
\hline DJIBSC & 0.3202 & 0.3173 & 0.8245 & 0.8167 & 0.7863 & 1.0000 & & & & & & & & & \\
\hline DJICYC & -0.0222 & 0.1076 & 0.8101 & 0.7145 & 0.8106 & 0.5587 & 1.0000 & & & & & & & & \\
\hline DJINCY & 0.0685 & 0.1698 & 0.8368 & 0.7864 & 0.7945 & 0.7077 & 0.7145 & 1.0000 & & & & & & & \\
\hline DJIENE & 0.1829 & 0.4452 & 0.7467 & 0.7223 & 0.7482 & 0.7499 & 0.5144 & 0.6290 & 1.0000 & & & & & & \\
\hline DJIFIN & 0.0174 & 0.0983 & 0.5763 & 0.4797 & 0.5474 & 0.4415 & 0.5517 & 0.5091 & 0.4143 & 1.0000 & & & & & \\
\hline DJIHCR & 0.0281 & 0.1112 & 0.7433 & 0.7074 & 0.7489 & 0.5396 & 0.6476 & 0.7138 & 0.5631 & 0.3828 & 1.0000 & & & & \\
\hline DJIIDU & 0.0868 & 0.2419 & 0.9447 & 0.8755 & 0.9307 & 0.7860 & 0.7732 & 0.7800 & 0.6556 & 0.5790 & 0.6269 & 1.0000 & & & \\
\hline DJITEC & -0.0077 & 0.1475 & 0.7833 & 0.6913 & 0.8518 & 0.4960 & 0.7054 & 0.5380 & 0.4307 & 0.4352 & 0.5111 & 0.7747 & 1.0000 & & \\
\hline DJITLS & 0.0834 & 0.1749 & 0.7667 & 0.7606 & 0.7538 & 0.5952 & 0.6021 & 0.6066 & 0.4971 & 0.4393 & 0.5265 & 0.7123 & 0.5922 & 1.0000 & \\
\hline DJIUTI & 0.1568 & 0.2781 & 0.6826 & 0.7019 & 0.6459 & 0.6716 & 0.4435 & 0.5700 & 0.6449 & 0.3519 & 0.5133 & 0.6137 & 0.3689 & 0.5593 & 1.0000 \\
\hline
\end{tabular}

\subsection{The DECO-FIAPARCH model}

Engle (2002) develops the dynamic conditional correlation (DCC)-GARCH model, which offers flexibility to simultaneously model the multivariate conditional volatility of stock returns and their time-varying correlations. Despite its flexibility, the DCC estimation involves computing the correlation of too many pairs sampled $n(n-1) / 2$ times, which produces results that are difficult to interpret (Aboura and Chevallier, 2014). To overcome this limitation, Engle and Kelly (2012) propose to use the DECO-GARCH model, which can eliminate the computational and presentational difficulties of high-dimension systems (Pan et al., 2016). The DECO model is a special version of the DCC model in which the correlations across all pairs of assets are equal but the common equicorrelation is timevarying. Another advantage of equicorrelation is that it provides superior forecasting ability during the crisis periods across the various portfolios (Clements et al., 2014).

The AR(1) model in which the dynamics of current stock returns are explained by their lagged returns is defined as follows:

$r_{t}=\mu+\xi r_{t-1}+\varepsilon_{t}, t \in T$ with $\varepsilon_{t}=z_{t} \sqrt{h_{t}}$

where $|\mu| \in[0 \infty),|\xi|<1$ and the innovations $\left\{z_{t}\right\}$ follow the Student's t-distribution $\left(z_{t} \sim S T(0,1, v)\right)$. The Student's t-distribution is estimated with the parameter $(\nu)$, which represents the number of degrees of freedom (df) and measures the degree of leptokurtosis displayed by the density (Fiorentini et al., 2003). The conditional variance $h_{t}$ is positive with probability one and is a measurable function of the variance-covariance matrix $\Sigma_{t-1}$.

The FIAPARCH $(p, d, q)$ model of Tse (1998) is formally expressed as follows:

$h_{t}^{\delta / 2}=\omega[1-\beta(L)]^{-1}+\left[1-[1-\beta(L)]^{-1} \phi(L)(1-L)^{d}\right]\left(\left|\varepsilon_{t}\right|-\lambda \varepsilon_{t}\right)^{\delta}$,

where $\omega, \beta, \phi$, and $d$ are the parameters to be estimated. The parameter $d$ where $0 \leq d \leq 1$ measures the long-range memory in the conditional volatility, $L$ denotes the lag operator, $\delta$ is the power term of returns for the predictable structure in the volatility persistence, and $\lambda>0$ represents the asymmetry parameter indicating that negative shocks give rise to higher volatility than positive shocks of equal size.

We follow Engle (2002) to obtain the dynamic conditional correlations. We assume that $E_{t-1}\left[\varepsilon_{t}\right]=0$ and, $E_{t-1}\left[\varepsilon_{t} \varepsilon_{t}{ }^{\prime}\right]=H_{t}$, where $E_{t}[\cdot]$ is the conditional expectation on using the information set available at time $t$. The conditional variance-covariance matrix, $H_{t}$, can be written as:

$H_{t}=D_{t} R_{t} D_{t}$ where $D_{t}=\operatorname{diag}\left(h_{11, t}^{1 / 2}, \cdots, h_{N N, t}^{1 / 2}\right)$ is the $N \times N$ diagonal matrix of conditional standard deviations of the residuals, which are obtained from taking the square root of the conditional variance modelled by an univariate $\operatorname{AR}(1)$-FIAPARCH( $1, d, 1)$ model. Moreover, $R_{t}$ is a matrix of time-varying conditional correlations, which is given by:

$R_{t}=\left\{Q_{t}^{*}\right\}^{-1 / 2} Q_{t}\left(Q_{t}^{*}\right)^{-1 / 2}$

$Q_{t}^{*}=\operatorname{diag}\left[Q_{t}\right]$,

$Q_{t}=\left[q_{i j, t}\right]=(1-a-b) S+a u_{t-1} u_{t-1}^{\prime}+b Q_{t-1}$,

where $u_{t}=\left[u_{1, t}, \cdots, u_{n, t}\right]^{\prime}$ is the standardized residuals (i.e. $u_{i, t}=\varepsilon_{i, t} / h_{i, t}$ ), $S \equiv\left[s_{i, j}\right]=E\left[u_{t} u_{t}^{\prime}\right]$ is the $n \times n$ unconditional covariance matrix of $u_{t}$, and $a$ and $b$ are non-negative scalars satisfying $a+b<1$ ). The resulting model is called the DCC model.

In this context, Aielli (2013) proves that the estimation of the covariance matrix $Q_{t}$ in this way is inconsistent because $E\left[R_{t}\right] \neq E\left[Q_{t}\right]$, and suggests the following consistent model (cDCC model) for the correlation-driving process:

$Q_{t}=(1-a-b) S^{*}+a\left(Q_{t-1}^{*}{ }^{1 / 2} u_{t-1} u_{t-1}^{\prime} Q_{t-1}^{*}{ }^{1 / 2}\right)+b Q_{t-1}$,

where $S^{*}$ is the unconditional covariance matrix of $Q_{t}^{* 1 / 2} u_{t}$

Engle and Kelly (2012) suggest that we model $\rho_{t}$ by using the cDCC process to obtain conditional correlation matrix $Q_{t}$ and then taking the mean of its off-diagonal elements. This approach, which reduces estimation time, is called the dynamic equicorrelation (DECO) model. The scalar equicorrelation is defined as:

$\rho_{t}^{D E C O}=\frac{1}{n(n-1)}\left(J_{n}^{\prime} R_{t}^{c D C C} J_{n}-n\right)=\frac{2}{n(n-1)} \sum_{i=1}^{n-1} \sum_{j=i+1}^{n} \frac{q_{i j, t}}{\sqrt{q_{i i, t} q_{j j, t}}},(8)$

where $q_{i j, t}=\rho_{t}^{D E C O}+a^{D E C O}\left(u_{i, t-1} u_{j, t-1}-\rho_{t}^{D E C O}\right)+b^{D E C O}\left(q_{i j, t}-\rho_{t}^{D E C O}\right)$, which is the $(i, j)^{\text {th }}$ element of the matrix $Q_{t}$ from the CDCC model. We then use this scalar equicorrelation to estimate the conditional correlation matrix:

$R_{t}=\left(1-\rho_{t}\right) I_{n}+\rho_{t} J_{n}$,

where $J_{n}$ is the $n \times n$ matrix of ones and $I_{n}$ is the $n$-dimensional identity matrix. 
Table 3

Estimation of the multivariate AR(1)-FIAPARCH(1,d,1)-DECO model.

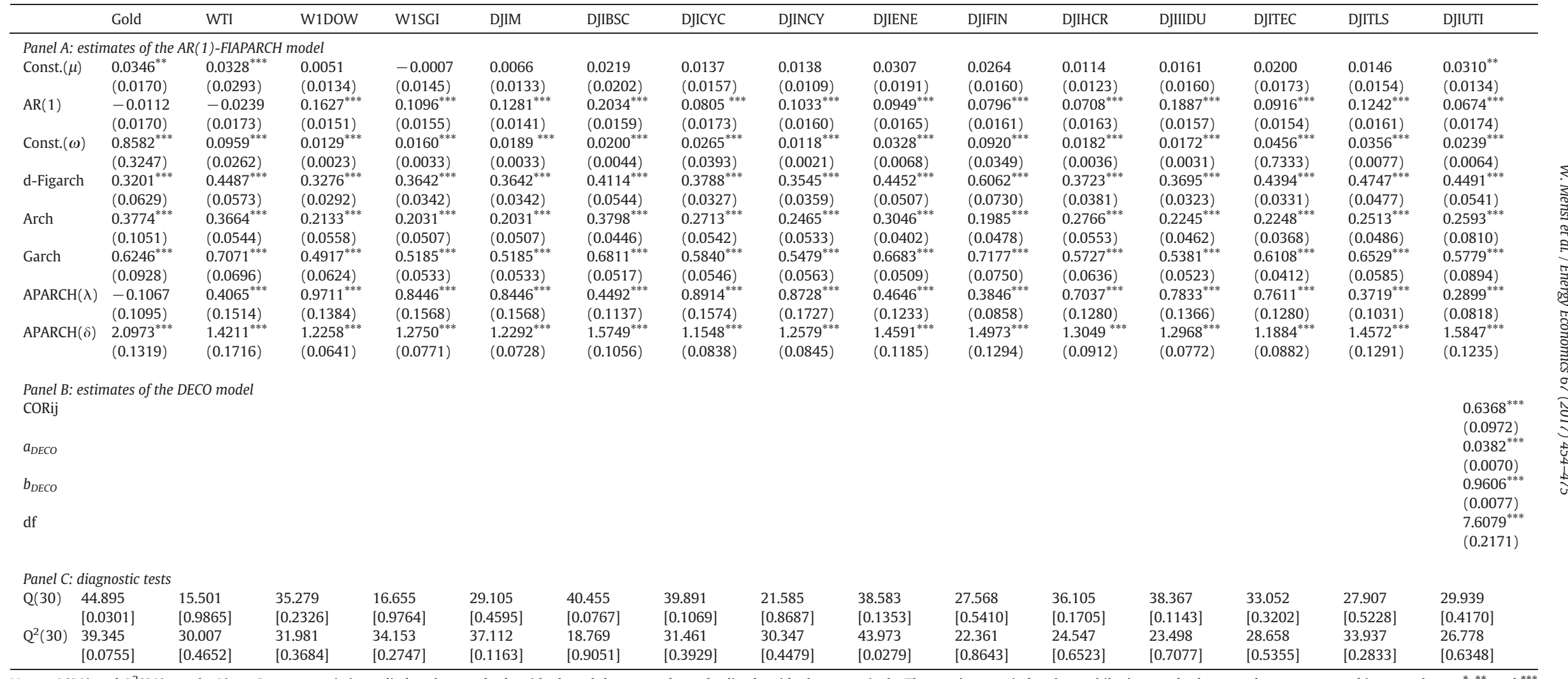

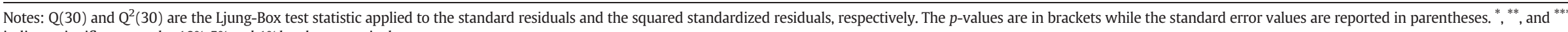
indicate significance at the $10 \%, 5 \%$ and $1 \%$ levels, respectively. 


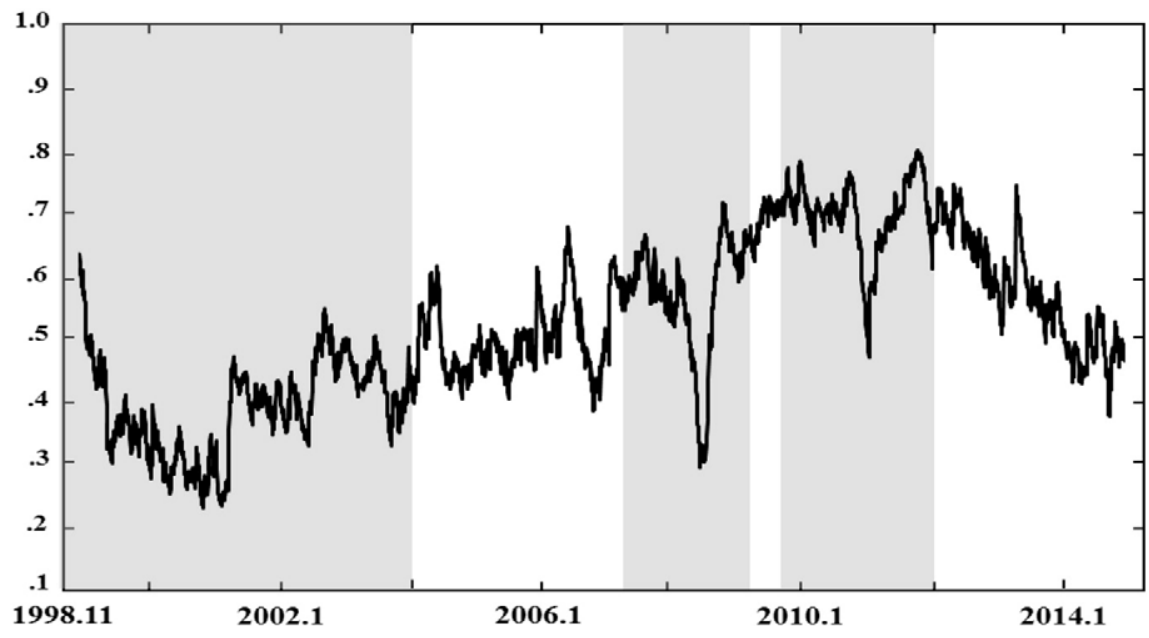

Fig. 2. Dynamic equicorrelation for the group.

Note that the estimation of the DECO model is carried out using a two-step maximum likelihood of the probability density function of a multivariate Student's t-distribution expressed as:

$$
\begin{aligned}
l_{t}(\Theta)= & \log \left\{\left(\Gamma\left(\frac{\nu+2}{2}\right) \nu\right) /\left((\nu \pi) \Gamma\left(\frac{\nu}{2}\right)(\nu-1)\right)\right\}-(1 / 2) \log \left(\left|H_{t}\right|\right)-(1 / 2) \\
& \times(\nu+2) \log \left[1+\left(\varepsilon_{t}^{\prime} H_{t}^{-1} \varepsilon_{t}\right) /(\nu-2)\right],
\end{aligned}
$$

where $\Gamma(\cdot)$ is the Gama function, $v$ is the degree of freedom for the Student's t-distribution, $H_{t}$ is a conditional variance-covariance matrix. $\Theta$ is a parameter vector with all of the coefficients of the DECOFIAPARCH model.

\subsection{Spillover index framework}

We apply the generalized VAR methodology, variance decomposition, and the generalized spillover index of Diebold and Yilmaz (2012) to examine the directional spillovers and net spillovers across the two commodity futures prices (Gold and WTI) and Islamic sector indices. Following Diebold and Yilmaz (2012), we assume a covariance stationary $n$-variable $\operatorname{VAR}(p)$ :

$y_{t}=\sum_{i=1}^{p} \Phi_{i} y_{t-1}+\varepsilon_{t}$,

where $y_{t}$ is the $n \times 1$ vector of endogenous variables, $\Phi_{i}$ are $n \times n$ autoregressive coefficient matrices, and $\varepsilon_{t}$ is a vector of error terms that are assumed to be serially uncorrelated. If the VAR system above is a covariance stationary, then a moving average representation is written as $y_{t}=\sum_{j=0}^{\infty} A_{j} \varepsilon_{t}$, where the $n \times n$ coefficient matrix $A_{j}$ obeys a recursion of the form $A_{j}=\Phi_{1} A_{j-1}+\Phi_{2} A_{j-2}+\ldots+\Phi_{p} A_{j-p}$, with $A_{0}$ being the $n \times n$ identity matrix and $A_{j}=0$ for $j<0$. The total, directional, and net spillovers are generated by generalized forecasterror variance decompositions of the moving average representation of the VAR model. The framework of generalized variance decompositions eliminates any dependence of the results on the ordering of the variables.

Koop et al. (1996) and Pesaran and Shin (1998) propose the following $H$-step-ahead generalized forecast-error variance decomposition:

$\theta_{i j}(H)=\frac{\sigma_{j j}^{-1} \sum_{h=0}^{H-1}\left(e_{i}^{\prime} A_{h} \Sigma e_{j}\right)^{2}}{\sum_{h=0}^{H-1}\left(e_{i}^{\prime} A_{h} \Sigma A_{h}^{\prime} e_{i}\right)}$ where $\Sigma$ is the variance matrix of the vector of errors $\varepsilon$, and $\sigma_{j j}$ is the standard deviation of the error term of the $j^{\text {th }}$ equation. Finally, $e_{i}$ is a selection vector with a value of one for the $i^{\text {th }}$ element, and zero otherwise. The spillover index yields a $n \times n$ matrix $\theta(H)=\left[\theta_{i j}(H)\right]$, where each entry gives the contribution of variable $j$ to the forecast error variance of variable $i$. Own-variable and cross-variable contributions are contained in the main diagonal and the off-diagonal elements of $\theta(H)$ matrix, respectively.

Because the own- and cross-variable variance contribution shares do not sum to one under the generalized decomposition (i.e., $\sum_{j=1}^{n} \theta_{i j}(H) \neq 1$ ), each entry of the variance decomposition matrix is normalized by its row sum as follows:

$\theta_{i j}(H)=\frac{\theta_{i j}(H)}{\sum_{j=1}^{n} \theta_{i j}(H)}$,

with $\sum_{j=1}^{n} \widetilde{\theta}_{i j}(H)=1$ and $\sum_{i, j=1}^{n} \widetilde{\theta}_{i j}(H)=n$ by construction.

This allows us to define a total spillover index as:

$T S(H)=\frac{\sum_{i, j=1, i \neq}^{n} \tilde{\theta}_{i j}(H)}{\sum_{i, j=1}^{n} \tilde{\theta}(H)} \times 100=\frac{\sum_{i, j=1, i \neq j}^{n} \tilde{\theta}_{i j}(H)}{n} \times 100$

This index measures the average contribution of spillovers from shocks in all (other) markets to the total forecast error variance. Additionally, this index is flexible and enables the identification of the directional spillovers among all markets. Specifically, the directional spillovers received by market $i$ from all other markets $j$ are defined as:

$D S_{i \leftarrow j}(H)=\frac{\sum_{i, j=1, i \neq j}^{n} \tilde{\theta}_{i j}(H)}{\sum_{i, j=1}^{n} \tilde{\theta}_{i j}(H)} \times 100=\frac{\sum_{i, j=1, i \neq j}^{n} \tilde{\theta}_{i j}(H)}{n} \times 100$

Similarly, the directional spillovers transmitted by market $i$ to all other markets $j$ are defined as:

$D S_{i \rightarrow j}(H)=\frac{\sum_{i, j=1, i \neq j}^{n} \tilde{\theta}_{j i}(H)}{\sum_{i, j=1}^{n} \tilde{\theta}_{j i}(H)} \times 100=\frac{\sum_{i, j=1, i \neq j}^{n} \tilde{\theta}_{j i}(H)}{n} \times 100$

The set of directional spillovers provides a decomposition of total spillovers into those coming from (or to) a particular market. For instance, in the present application this means that this spillover matrix $\theta(H)$ consists of the main diagonal elements reflecting 

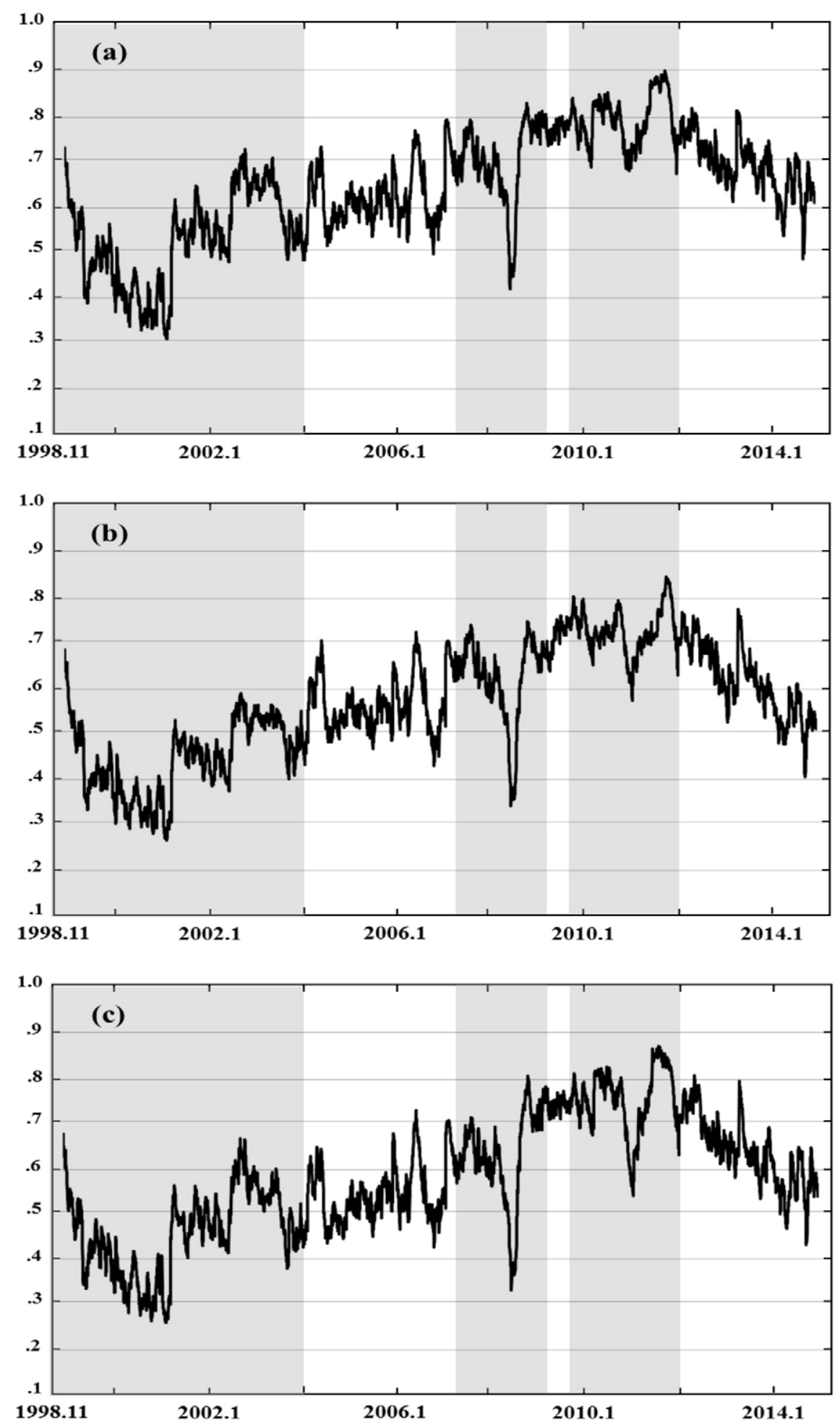

Fig. 3. Dynamic equicorrelation for stock indices and commodity futures; (a) within stocks; (b) gold-stocks; (c) WTI-stocks.

own-market spillovers, and the off-diagonal elements reflecting cross-market spillovers.

Finally, subtracting Eq. (16) from Eq. (15), we compute the net volatility spillovers from each market to all other markets as:

$N S_{i}(H)=D S_{i \rightarrow j}(H)-D S_{i \leftarrow j}(H)$

The net spillovers demonstrate whether a market is a receiver or transmitter of spillovers in net terms. It is also our interest to examine the net pairwise spillovers (NPS) as following:

$$
\operatorname{NPS}_{i j}(H)=\left[\frac{\tilde{\theta}_{j i}(H)}{\sum_{i, k=1}^{n} \tilde{\theta}_{j k}(H)}-\frac{\tilde{\theta}_{i j}(H)}{\sum_{j, k=1}^{n} \tilde{\theta}_{j k}(H)}\right] \times 100
$$

The net pairwise spillover between markets $i$ and $j$ is simply the difference between the gross shocks transmitted from market $i$ to market $j$ and those transmitted from $j$ to $i$. 
Table 4

Total volatility spillovers.

\begin{tabular}{|c|c|c|c|c|c|c|c|c|c|c|c|c|c|c|c|c|}
\hline \multirow[t]{2}{*}{ To $(i)$} & \multirow[b]{2}{*}{ GOLD } & \multirow[b]{2}{*}{ WTI } & \multirow[b]{2}{*}{ W1D0W } & \multirow[b]{2}{*}{ W1SGI } & \multirow[b]{2}{*}{ DJIM } & \multirow[b]{2}{*}{ DJIBSC } & \multirow[b]{2}{*}{ DJICYC } & \multirow[b]{2}{*}{ DJINCY } & \multirow{2}{*}{$\frac{\operatorname{From}(j)}{\text { DJIENE }}$} & \multirow[b]{2}{*}{ DJIFIN } & \multirow[b]{2}{*}{ DJIHCR } & \multirow[b]{2}{*}{ DJIIDU } & \multirow[b]{2}{*}{ DJITEC } & \multirow[b]{2}{*}{ DJITLS } & \multirow[b]{2}{*}{ DJIUTI } & \multirow[b]{2}{*}{ From others } \\
\hline & & & & & & & & & & & & & & & & \\
\hline GOLD & 65.95 & 0.58 & 3.67 & 3.12 & 2.78 & 4.07 & 2.89 & 2.72 & 2.73 & 2.78 & 1.21 & 3.74 & 0.61 & 1.16 & 2 & 34 \\
\hline WTI & 1.03 & 41.67 & 4.78 & 4.59 & 4.24 & 3.13 & 3.99 & 4.33 & 7.17 & 9.24 & 3.16 & 4.51 & 2.49 & 2.46 & 3.23 & 58.3 \\
\hline W1D0W & 0.72 & 1.71 & 12.06 & 10.58 & 11.11 & 8.11 & 6.61 & 7.8 & 6.96 & 2.38 & 7.02 & 10.19 & 3.84 & 4.19 & 7.71 & 88.9 \\
\hline W1SGI & 0.65 & 1.87 & 11.97 & 12.29 & 10.89 & 7.44 & 6.16 & 8.12 & 6.56 & 1.88 & 7.7 & 9.49 & 3.48 & 4.55 & 7.95 & 88.7 \\
\hline DJIM & 0.58 & 1.67 & 11.8 & 9.93 & 11.92 & 7.67 & 6.59 & 7.56 & 6.64 & 2.04 & 7.44 & 10.03 & 4.97 & 4.43 & 7.72 & 89.1 \\
\hline DJIBSC & 1.05 & 1.51 & 10.26 & 9.25 & 9.41 & 11.95 & 5.29 & 7.4 & 9.85 & 3.7 & 6.08 & 9.01 & 2.09 & 3.9 & 9.26 & 88.1 \\
\hline DJICYC & 0.88 & 1.13 & 9.84 & 7.65 & 9.74 & 5 & 16.79 & 7.32 & 4.71 & 4.42 & 7.36 & 9.82 & 6.55 & 4.87 & 3.9 & 83.2 \\
\hline DJINCY & 0.76 & 1.36 & 11.43 & 9.89 & 10.3 & 6.94 & 7.22 & 11.73 & 6.51 & 2.76 & 8.18 & 9.57 & 3.12 & 3.79 & 6.42 & 88.3 \\
\hline DJIENE & 0.75 & 2.24 & 10.19 & 9.07 & 9.68 & 8.58 & 5.54 & 8 & 11.05 & 3.27 & 7.86 & 8 & 2.28 & 4 & 10.5 & 90 \\
\hline DJIFIN & 1.68 & 1 & 7.98 & 5.56 & 7.16 & 6.91 & 8.33 & 6.81 & 7.5 & 21.03 & 5.47 & 7.84 & 2.89 & 3.41 & 7.43 & 80 \\
\hline DJIHCR & 0.5 & 1.12 & 9.91 & 8.69 & 9.87 & 5.25 & 7.69 & 9.85 & 6.18 & 2.32 & 17.26 & 7.32 & 3.97 & 3.98 & 6.07 & 82.7 \\
\hline DJIIDU & 0.78 & 1.77 & 11.61 & 9.89 & 11.03 & 7.73 & 7.08 & 7.24 & 6.47 & 2.66 & 5.84 & 12.37 & 4.87 & 4.58 & 6.09 & 87.6 \\
\hline DJITEC & 0.21 & 1.76 & 9.23 & 6.94 & 12.69 & 2.57 & 8.72 & 3.9 & 2.45 & 1.59 & 4.91 & 10.28 & 26.26 & 6.81 & 1.67 & 73.7 \\
\hline DJITLS & 0.6 & 1.66 & 9.02 & 9.86 & 9.89 & 4.29 & 5.44 & 6.76 & 4.91 & 1.39 & 8.61 & 6.4 & 5.1 & 18.2 & 7.88 & 81.8 \\
\hline DJIUTI & 0.73 & 1.69 & 10.19 & 9.08 & 9.37 & 8.45 & 4.64 & 7.78 & 7.59 & 2.43 & 7.29 & 7.46 & 2.33 & 3.5 & 17.46 & 82.5 \\
\hline To others & 10.9 & 21.1 & 131.9 & 114.1 & 128.1 & 86.2 & 86.2 & 95.6 & 86.2 & 42.9 & 88.1 & 113.7 & 48.6 & 55.6 & 87.8 & 1196.9 \\
\hline All & 76.9 & 62.8 & 143.9 & 126.4 & 140.1 & 98.1 & 103 & 107.3 & 97.3 & 63.9 & 105.4 & 126 & 74.9 & 73.8 & 105.3 & Total: $79.79 \%$ \\
\hline
\end{tabular}

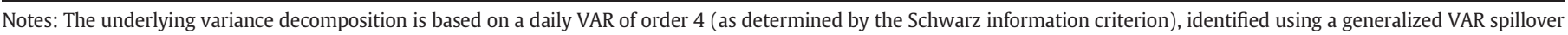

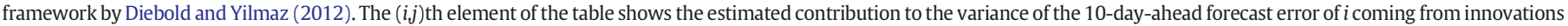

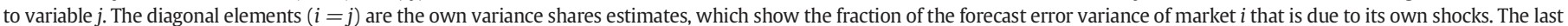

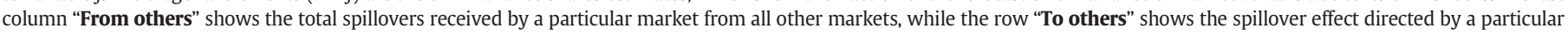
market to all other markets. The lower right corner "Total" indicates the level of total spillovers.

\section{Data and preliminary analysis}

\subsection{Data}

We use daily closing spot price data for gold, WTI crude oil and the aggregate and disaggregate Dow Jones Islamic sectoral indexes. The WTI futures crude oil benchmark, the reference crude for the United States, is traded on NYMEX. Concerning the Islamic equities, they include the aggregate Dow Jones Islamic Market (DJIM) Index and the associated ten disaggregate sectors including Basic Materials, the Consumer Services, the Consumer Goods, the Energy, the Financials, the Health Care, the Industrials Index, the Technology, the Telecommunications, the Utilities. ${ }^{5}$ For comparison purposes, we consider the conventional Dow Jones global index (W1DOW) and Dow Jones sustainability world index (W1SGI).

The study period runs from November 9, 1998 through March 5, 2015. This period is marked by several episodes of wide instabilities for commodity prices (e.g., spectacular increases (plunges) in oil prices throughout 2007 and early 2008 (2014-2015) and food price surges during 2007-2008), major events (e.g., the Gulf wars and the $9 / 11 / 2001$ terrorist attack) and three severe crises (e.g., the 2008-2009 GFC and the 2010-2012 ESDC).

The closing oil prices are expressed in USD/barrel and complied from the US Energy Information Administration (EIA) website (www.eia. gov), while the gold time series is extracted from the World Gold Council website (https://www.gold.org/). The data for the Islamic stock index series are extracted from Bloomberg.

We select oil and gold because they have extensive economic impacts on financial activities and since their roles are crucial in affecting international stock markets. In the flight-to-quality literature, for example, gold is well known for its role as a safe haven asset (Baur and Lucey, 2010; Baur and McDermott, 2010). This valuable yellow metal is highly liquid and is used as a good vehicle of investment. Oil because of its extensive forward and backward linkages with economic sectors is strongly related to stock markets. Oil prices instability may draw unexpected shifts in returns and volatility of stock markets. Hence, the relationship between these markets is quite complex and deserves a further analysis, particularly at the sectoral level.

\footnotetext{
5 Table A1 in the Appendix summarizes the notations of these Islamic sectoral indexes, and the DJ aggregate conventional and sustainability indexes.
}

As an illustration, Fig. 1 shows the dynamics of return series under consideration during the sample period. We see that the commodity and stock returns are especially volatile after the mid-2008. The volatility clustering of oil market is more pronounced than gold market.

\subsection{Preliminary analysis}

We calculate the continuously compounded daily returns by taking the difference in the logarithms of two consecutive prices. Table 1 presents the descriptive statistics of the daily commodity, conventional Dow Jones global, Dow Jones sustainability equity index and Dow Jones Islamic (aggregate and sectors) stock return series. As shown in this table, the average daily returns are positive for all return series. Additionally, gold reveals the highest average returns, while the utilities present the lowest average returns. The unconditional volatility as measured by the standard deviation ranges is the highest for oil, followed by the technology index and the financial index. The gold price, the health care index and the consumer goods index are the least volatile among all indices. Note that the Dow Jones sustainability equity index is more volatile than both the conventional and Islamic (aggregate) equity indexes. The skewness coefficients are negative for the majority of the return series with the exception of the telecommunications, technology and utilities index return. The kurtosis coefficients are above three for all the return series which is the value for the Gaussian distributions. These findings show that the probability distributions of all return series are skewed and leptokurtic, thus rejects the normal distribution which is also confirmed by the Jarque-Bera statistic (JB). Further, we apply the conventional augmented Dickey and Fuller (1979) and the Phillips and Perron (1988) unit root statistics, and the stationarity property under the null using the Kwiatkowski et al. (1992) test. The results indicate that all return series are stationary.

Further, we examine the existence of the ARCH effects, which shows that all return series exhibit the ARCH behavior, underscoring that some stylized facts such as fat-tails, clustering volatility and persistence characterize the commodity and Islamic stock sector returns. Table 2 presents the results of the unconditional correlation levels between the conventional Dow Jones stock index, Dow Jones sustainability stock index, aggregate Islamic stock index, Islamic stock sectoral indices, oil and gold market returns. The results show that the correlations between gold and Islamic stock sector index returns are close to zero or negative. In contrast, the correlations between oil and the Islamic index returns are 


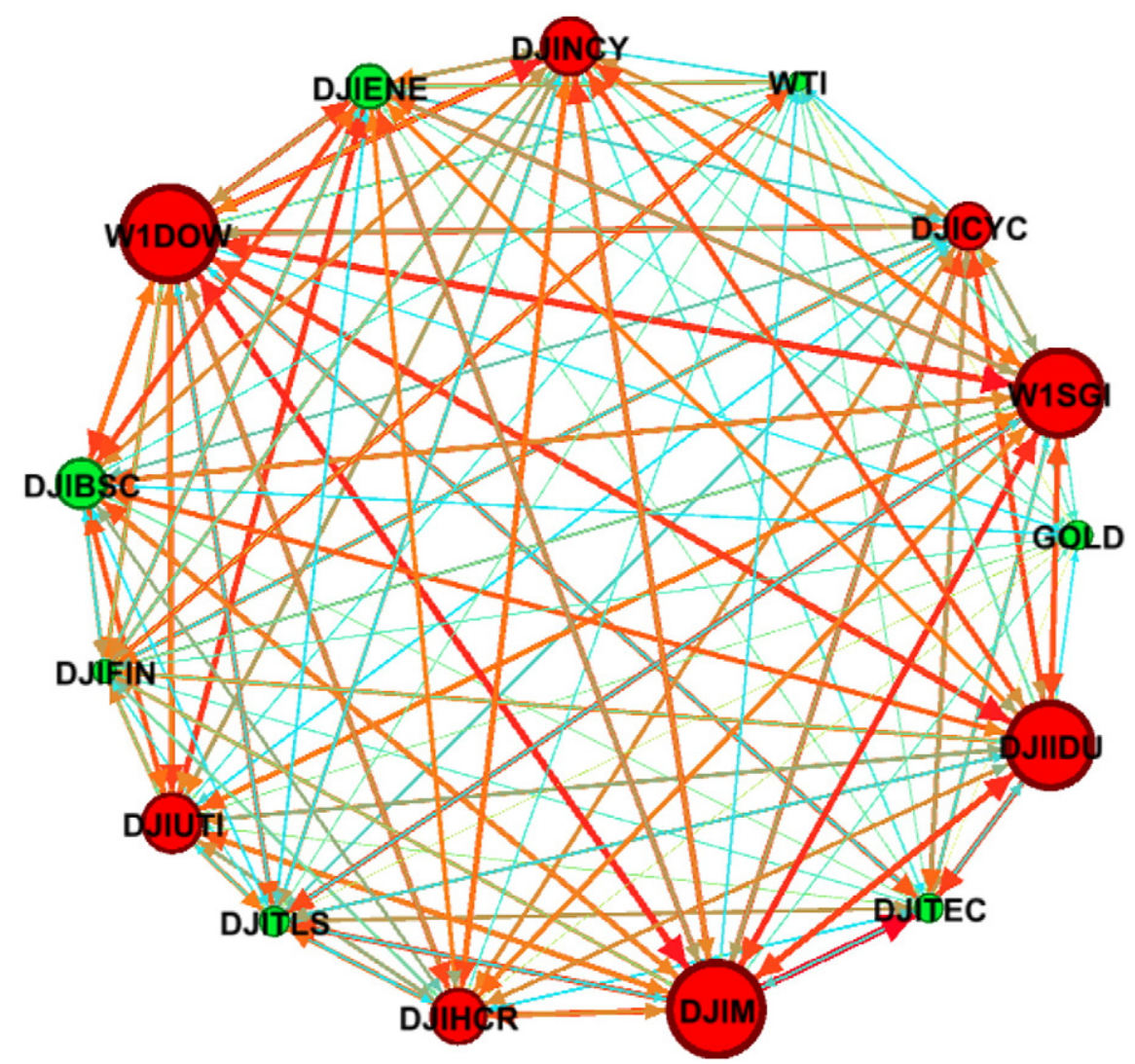

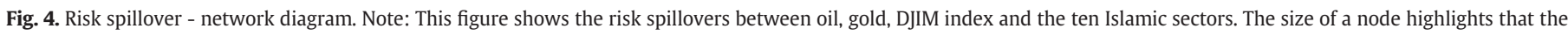

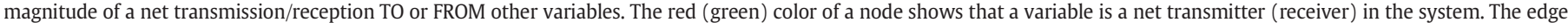
size underscores the magnitude of the pair-wise spillover, while the magnitude is also reflected through the color type (light blue (weak), orange (medium), red (strong)).

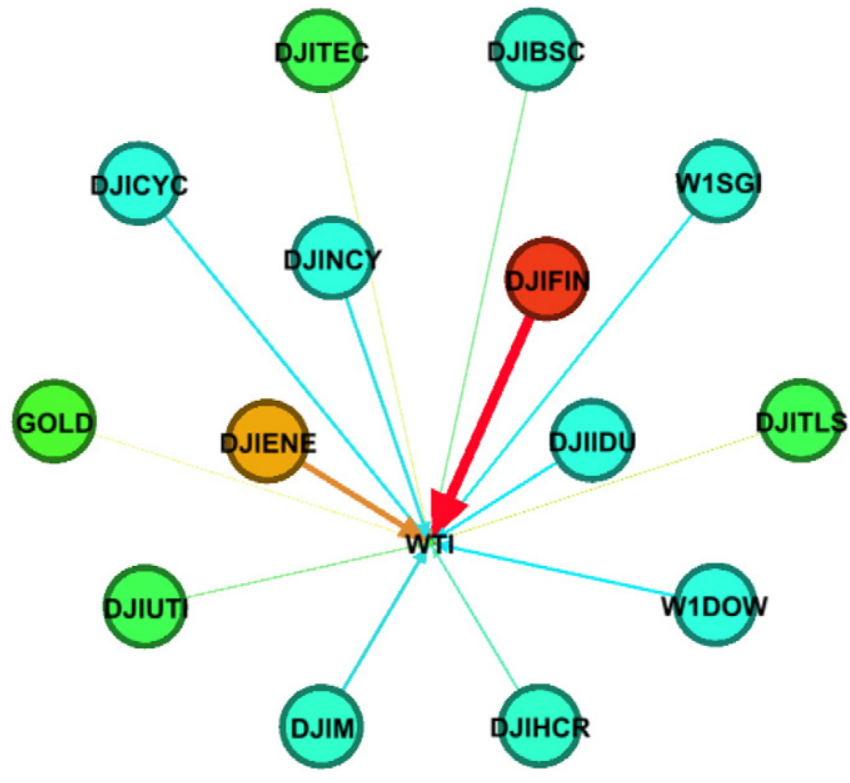

Fig. 5. Net pair-wise directional spillovers between oil, the conventional index, the sustainability index and the DJIM index and their corresponding ten sectors- network diagram. Note: The figure shows the net pair-wise directional spillovers between oil and both the aggregate and the disaggregate Islamic stock markets. The colors of the nodes indicate the magnitude of net transmitters (red (strong), orange (medium), light blue (weak) and green (very weak). The edge size shows the magnitude of the pair-wise spillovers. The edge arrow indicates pairwise directional connectedness. positive and weak for all pairs. Similar results are found for correlations of the conventional stock index and the Dow Jones sustainability stock index with commodity markets as these correlations are positive and weak. More precisely, for the gold market, the highest correlation is with the energy sector, followed by the basic materials, while the lowest correlation is for the technology-gold pair followed by the consumer services-gold pair. Looking at the WTI crude, this market presents the highest (lowest) correlation with energy and basic materials (financial and consumer services) sectors. These results may be explained by the differences in the market concentration of some sectors. In fact, the basic materials sector is characterized by high market concentration. More interestingly, the Islamic stock sectoral indices are less correlated with gold than oil, implying the presence of more portfolio diversification benefits using the yellow metal than the black gold.

Finally, the long memory test results reveal the presence of long memory behavior for all squared return series (as a proxy variable of volatility), which clearly supports our decision to use the fractionally integrated APARCH-based approach to examine the issue of time-varying correlations among the markets under consideration. The results are available upon request.

\section{Empirical results and policy implications}

\subsection{Marginal model results}

To select the best marginal model, we examine different GARCH models (standard GARCH, FIGARCH, FIEGARCH and FIEGARCH) by considering different combinations of the parameters $p, q, r$ and $m$ for values ranging from zero to a maximum lag of 2 . Table 3 presents the estimated results of the marginal model. The estimates of the univariate FIAPARCH model (Panel A) show that the one-lagged returns of the mean equation 


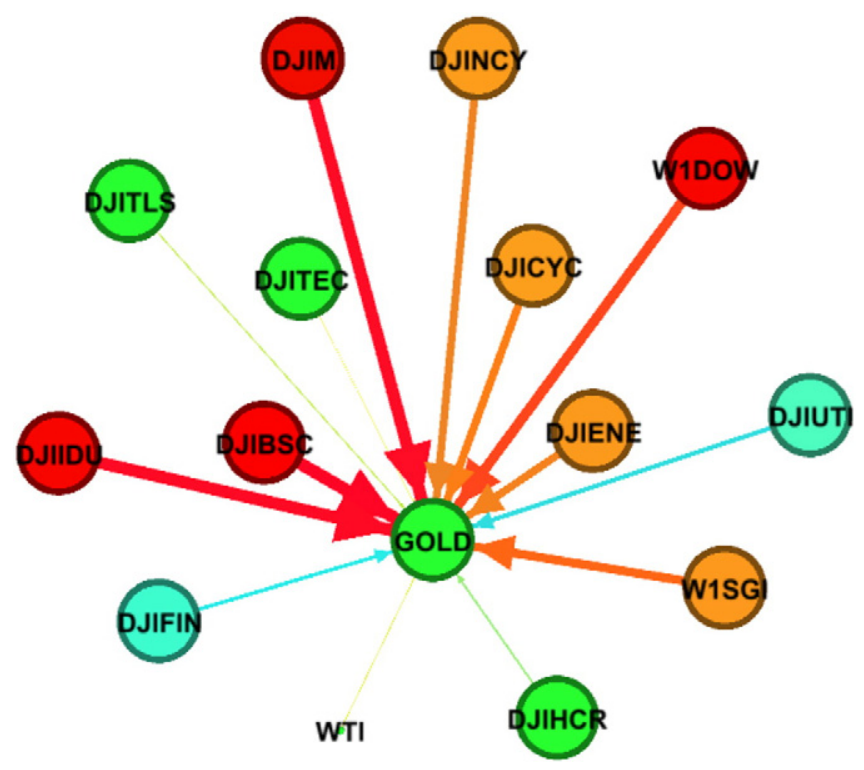

Fig. 6. Net pair-wise directional spillovers between gold, DJIM and both conventional, sustainability and the ten Islamic sectors- network diagram. Note: The figure shows the net pair-wise directional spillovers between gold and both the aggregate and disaggregate Islamic stock markets. The size of a node shows the magnitude of a net transmission/reception TO/FROM gold. The colors of the nodes indicate the magnitude of net transmitters (red (strong), orange (medium), light blue (weak) and green (very weak). The edge size underscores the magnitude of the pair-wise spillovers. The edge arrow indicates pairwise directional connectedness.

are positive and statistically significant at the $1 \%$ level for all stock returns (but not for gold and oil), indicating that the historical returns are instantaneously and rapidly embodied in the current returns for these stock markets. Moreover, the fractionally integrated coefficient $(d)$ is significant for all the markets considered, revealing a high level of persistence. Among the commodity markets, the highest $(d)$ parameter is bestowed on the WTI crude oil. Concerning the Islamic stock sectoral market indexes, the lowest long memory parameter is for the industrial sector, while the financial sector is the highest persistent sector. These results reflect the relative dissimilarity of weights between the sectors in the aggregate DJIM index.
Looking at the aggregate level, the conventional Dow Jones stock index is less persistent than both the Dow Jones sustainability and DJIM indexes. Moreover, the degree of freedom (df) of the Student t-distributions are significant at the $1 \%$ level, suggesting that the tails of the error terms are heavier than those of the normal distribution. This result thus indicates that using the Student t-distribution to deal with these properties is appropriate.

Panel B of Table 3 presents the estimates of the DECO process. The $a_{D E C O}$ and $b_{D E C O}$ coefficients are positive and significant at the $1 \%$ level. This finding emphasizes the importance of shocks between the commodity and the Islamic stock sectoral markets. Furthermore, the $b_{D E C O}$ parameter is significant and very close to one, revealing a higher persistence of volatility across the considered markets. It is worth noting that the significance of the parameters $a_{D E C O}$ and $b_{D E C O}$ indicates the appropriateness of the DECO-FIAPARCH model in modeling the time-varying equicorrelations between the considered markets. Moreover, the sums of $a_{D E C O}$ and $b_{D E C O}$ coefficients are $<1$, indicating that the estimated DECO parameters lie within the range of typical estimates from the GARCH model. However, the dynamic equicorrelation is statistically significant at the $1 \%$ level. It is positive and less than one, suggesting the presence of diversification benefits. Investors can thus have the opportunity to allocate their portfolio in distinctive sectors.

The diagnostic tests summarized in Panel C show no evidence of misspecification in our marginal model. In fact, the Ljung-Box test statistics for the standardized residuals and the squared standardized residuals do not reject the null hypothesis of no serial correlation for most cases.

Fig. 2 displays the dynamic equicorrelation for the group of the commodity, conventional, sustainability and both aggregate and disaggregate Islamic stock markets. As shown in this figure, we observe positive time-varying equicorrelations for the commodity and Islamic stock markets over the sample period. This result reveals that investors frequently change their portfolio structure by rebalancing their portfolios. More importantly, we identify three regimes for which the correlations between the markets change significantly. The highest level of the three correlation regimes are observed at the end of the 1997-1998 Asian financial crisis and the resulting 2000 default of the Long Term Capital Management Fund, the 2008-2009 GFC and the 2010-2012 ESDC, showing decreased opportunities for diversification benefits during those turmoil periods. During the burst of the dot-com bubble of 2001, we observe a little bit increase in the correlations

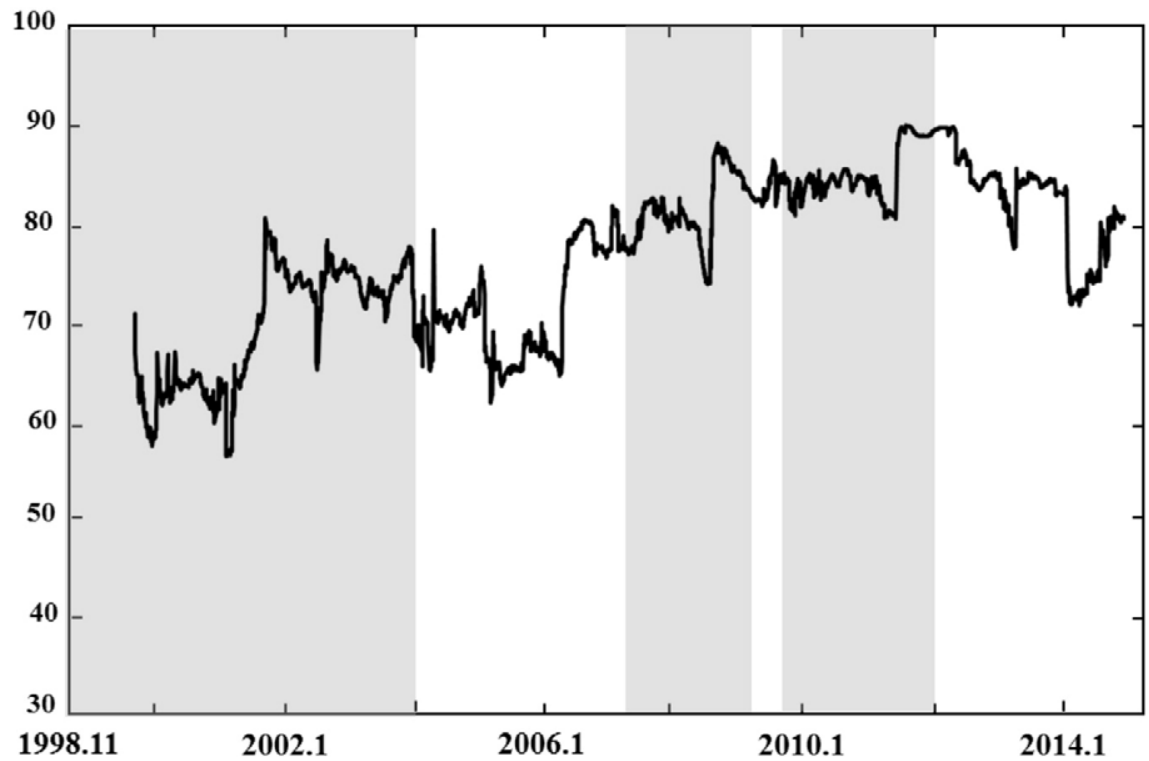

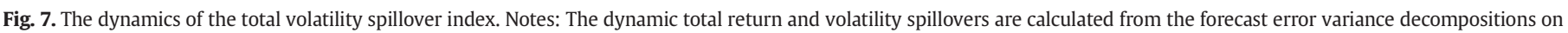
10 -step-ahead forecasts. The total spillover indices are estimated using 200-day rolling windows. 


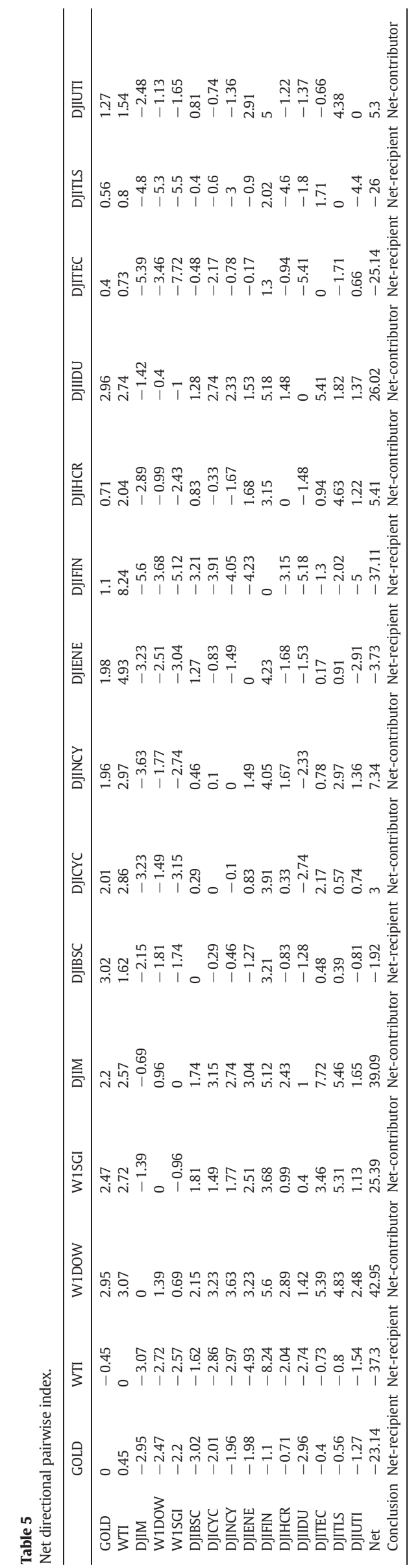

between the considered markets, confirming the recoupling hypothesis. This significant increase in the cross-market correlations after a shock hits indicates a pure contagion or herding and may reflect a shift in investors' appetite for or aversion to risk. It is worth noting that this is a minor crisis comparing to the 1997-1998 Asian crisis and the 2007-2008 GFC episodes. More interestingly, we show that the correlations are positive along the sample period and reflect phases of decreases and increases. This means that changes in the volatility transmission imply changes in diversification opportunities. In fact, contagion decreases the role of oil and gold as potential vehicles for diversification benefits. Looking at the sample after 2012, we view a decrease in the correlations for all cases, which is an indication of the presence of diversification benefits. The dynamic equicorrelation varies approximately between 0.2 and 0.7 but with elevated levels during the 2008-2009 GFC and the 2010-2012 ESDC, supporting the contagion effects. ${ }^{6}$

Fig. 3 plots the time-varying equicorrelation for the stock indices, the oil-stock and the gold-stock blocks. Similarly to Fig. 2, we observe a variation in the correlations. Also, the trajectories of all blocks are similar but with differences in magnitude. Graphically, we see that the correlations between gold and stock are lower than those of only stock or oilstock. To sum up, investors investing in Islamic stock companies may see more benefits in diversifying and investing in the gold and oil markets. The presence of positive and increasing correlations underscores an increasing integration between commodity and Islamic stock markets during the last years.

\subsection{Total volatility spillover index and rolling-sample spillover analysis}

Table 4 summarizes the estimates of the total volatility spillover matrix. The $(i, j)$ th entry in each panel is the estimated contribution to the forecast-error variance of variable $i$ coming from innovations of market $j$. The row sums excluding the main diagonal elements (termed 'From others') and the column sums (termed 'To others') report the total spillovers to (received by) and from (transmitted by) each volatility.

The total volatility spillovers reach $79.79 \%$. Looking at the directional spillovers transmitted 'To others', gold has a much lower impact on the Islamic stock markets than the crude oil market does. In fact, gold contributes only $0.58 \%$ to the forecast-error variance of the DJIM index, $1.03 \%$ to the forecast-error variance of oil and $7.94 \%$ to those of the associated Islamic sectors, $0.72 \%$ to the conventional DJ global index, $0.65 \%$ to the DJ sustainability index, while oil contributes $1.67 \%$ to that of the DJIM index, $15.24 \%$ to those of the ten sectors and the remaining to both conventional and sustainability Dow Jones index.

Islamic stock indexes also contribute to the forecasting error variance of the gold metal and oil markets. In fact, the DJIM index contributes $128 \%$ to the remaining markets (oil, gold, conventional index, sustainability index and the ten sector indexes). This index also contributes $2.78 \%$ to the forecasting-error variance of gold and $4.24 \%$ to that of oil. Oil and gold respectively contribute $01.67 \%$ and $0.58 \%$ to the forecasting variance of the DJIM index. This result indicates that gold provides greater diversification benefits than oil market. On the other hand, oil acts as a price discovery tool for the DJIM index. Conventional DJ global index and sustainability index contributes significantly to the aggregate and disaggregate Islamic indexes.

Among the Islamic sectors, the consumer goods and the industrials are the highest net volatility contributors, while the finance, the technology and the telecommunication are the lowest contributors to

\footnotetext{
${ }^{6}$ Forbes and Rigobon (2002) define the contagion as a significant increase in crossmarket linkages after a shock to one country (or a group of countries). Thus, contagion does not occur if two markets show a high degree of comovement during both stability and crisis periods. The interdependence is used instead if strong linkages between the two economies exist in all states of the world. Ahmad et al. (2013) define the contagion as significant increases in cross market correlations during the turmoil period, while any continued increase in cross market correlation at high levels is referred to as interdependence.
} 

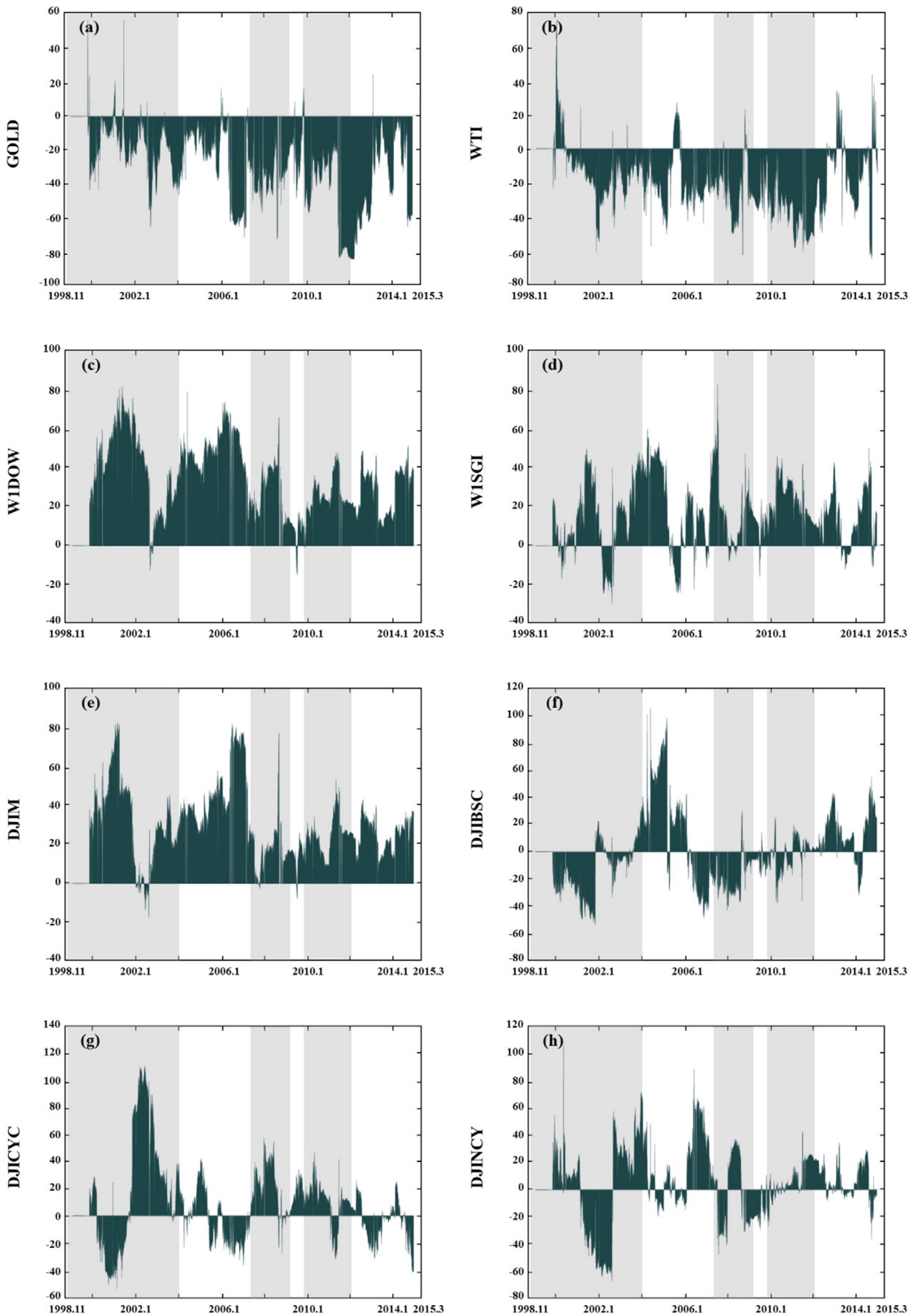

Fig. 8. Net volatility spillover index. Notes: The notations are defined in the appendix. 

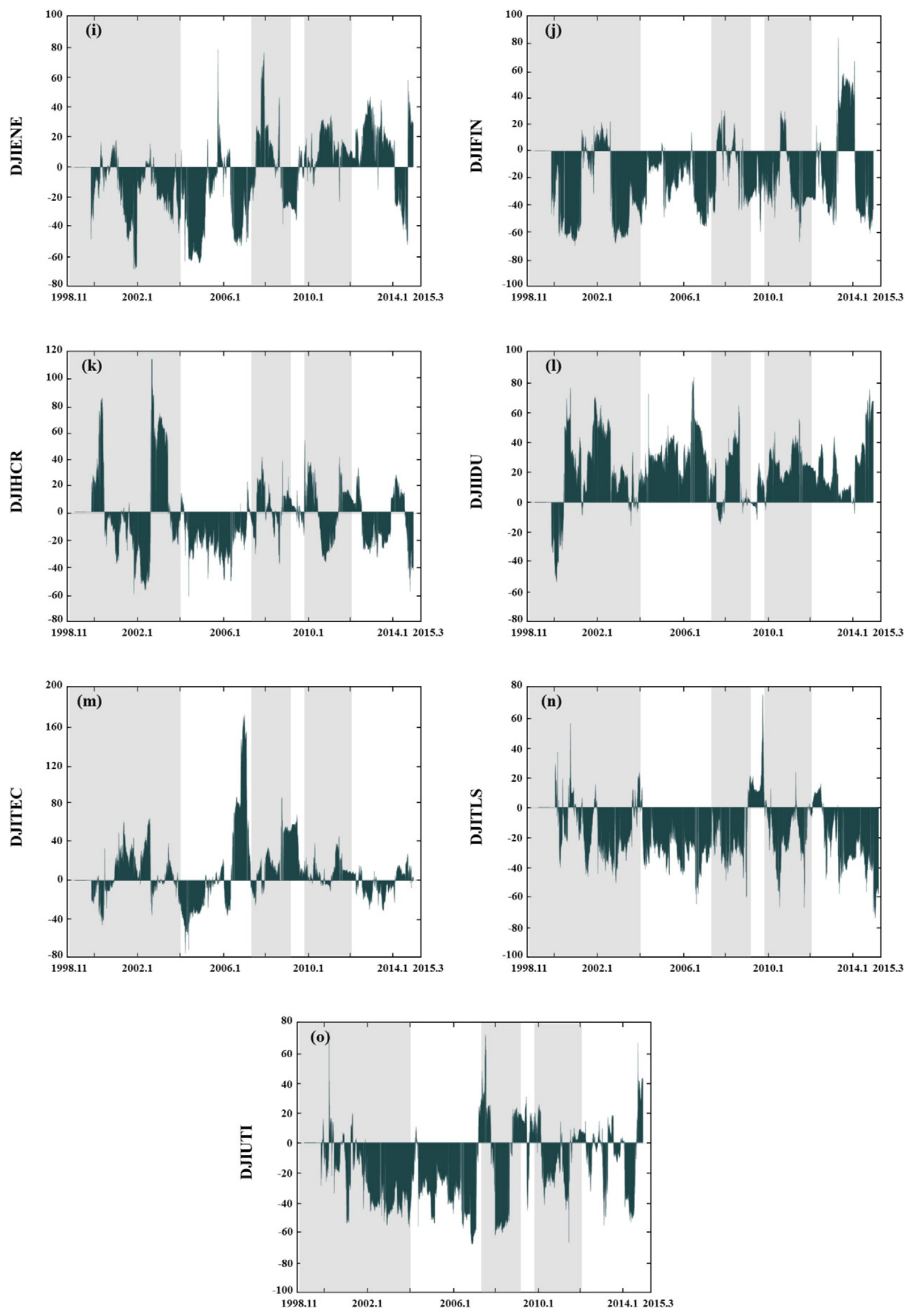

Fig. 8 (continued). 

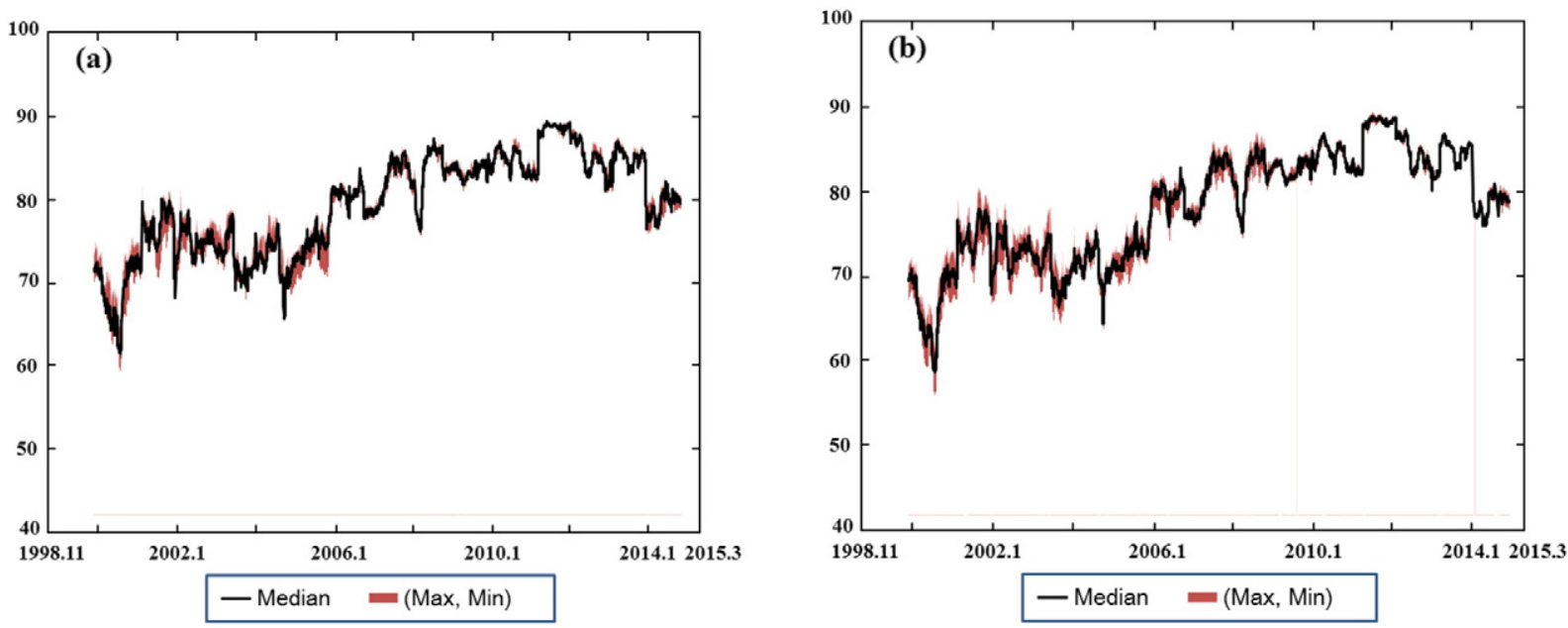

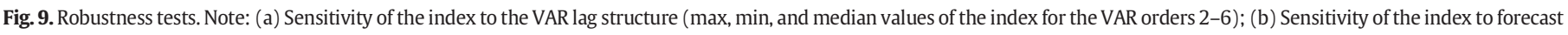
horizon (max, min, and median values over 5- to 10-day horizons).

volatility spillovers. Further, the risk spillovers between the Islamic stock sectoral markets are globally weak. Taking for example the industrial sector, the risk spillover coefficient varies between $6.4 \%$ for the telecommunications sector and $10.28 \%$ for the technology sector. For the utilities, health care and financial sectors, these sectors receive similar risk spillovers from the industrials. Looking at the telecommunications sector, one can see that this sector has similar spillovers to the rest of sectors, with the exception of technology. The interpretations of the remaining sectors are similar.

Fig. 4 plots the risk spillover network diagram and shows that conventional stock index, sustainability stock index, DJIM and the industrials sector are the most net contributors of risk spillovers, while the financials, basic materials, energy, technology, telecommunication, oil and gold sectors are among the largest net receivers of shocks from the rest of the markets. Figs. 5 and 6 display respectively the net pair- wise directional spillovers between the oil- stock and the gold- stock pairs. These figures synthetically display the main results for our dynamic analysis of the net pairwise directional connectedness. They provide a visualization of the complex network of innovation among 15 markets. In fact, they synthetically illustrate the main results of our analysis of the net directional connectedness using the DY's (2014) graphical methodology. We show that gold imports volatility from financial sectors, while oil imports volatility from the aggregate DJIM index and the cyclical basic materials and industrials sectors (see Figs. 5 \& 6).

Fig. 7 illustrates the evolution of the volatility spillover index. This figure shows that the total volatility spillovers increase and decrease over time. This result suggests that investors should modify their portfolio's structure accordingly. However, we provide evidence that the crises intensify the total volatility spillovers across the markets.

Table 6

Optimal portfolio weights and hedge ratios for the commodity futures and stock indices.

\begin{tabular}{|c|c|c|c|c|c|c|c|c|}
\hline \multirow[b]{2}{*}{ Pairs } & \multicolumn{4}{|c|}{ Optimal portfolio weights } & \multicolumn{4}{|c|}{ Hedge ratios } \\
\hline & Mean & St. Dev & Max & Min & Mean & St. dev & Max & Min \\
\hline W1DOW/Gold & 0.2793 & 0.3027 & 1.2199 & -0.2755 & 0.4220 & 0.1970 & 1.4105 & 0.0781 \\
\hline W1SGI/Gold & 0.3789 & 0.3168 & 1.2284 & -0.2589 & 0.4772 & 0.2283 & 1.4427 & 0.0908 \\
\hline DJIM/Gold & 0.3272 & 0.3032 & 1.1774 & -0.2352 & 0.3986 & 0.1886 & 1.3613 & 0.0733 \\
\hline DJIBSC/Gold & 0.5642 & 0.2644 & 1.2309 & -0.0373 & 0.5253 & 0.2668 & 2.0846 & 0.0965 \\
\hline DJICYC/Gold & 0.3682 & 0.1060 & 1.1652 & -0.2801 & 0.4232 & 0.1771 & 1.2900 & 0.0856 \\
\hline DJINCY/Gold & 0.0286 & 0.0753 & 0.5556 & -0.7481 & 0.1029 & 0.0829 & 0.7994 & 0.0049 \\
\hline DJIENE/Gold & 0.6086 & 0.2726 & 1.2083 & -0.1439 & 0.5606 & 0.2608 & 1.7918 & 0.1266 \\
\hline DJIFIN/Gold & 0.4819 & 0.3663 & 1.1941 & -0.2541 & 0.5169 & 0.3035 & 2.3506 & 0.1170 \\
\hline DJIHCR/Gold & 0.2672 & 0.3049 & 1.1430 & -0.2870 & 0.3658 & 0.1541 & 1.2167 & 0.0925 \\
\hline DJIIDU/Gold & 0.3832 & 0.2964 & 1.1945 & -0.2097 & 0.4235 & 0.2020 & 1.4379 & 0.0723 \\
\hline DJITEC/Gold & 0.5419 & 0.3492 & 1.1822 & -0.2353 & 0.5810 & 0.2882 & 2.2740 & 0.1226 \\
\hline DJITLS/Gold & 0.3726 & 0.3284 & 1.0777 & -0.2884 & 0.4343 & 0.1842 & 1.3179 & 0.0977 \\
\hline DJIUTI/Gold & 0.3195 & 0.2896 & 1.1558 & -0.2263 & 0.3962 & 0.1935 & 1.6526 & 0.0817 \\
\hline W1DOW/WTI & -0.0164 & 0.1312 & 0.7803 & -0.3227 & 0.2540 & 0.1377 & 0.8443 & 0.0479 \\
\hline W1SGI/WTI & -0.0501 & 0.1081 & 0.5589 & -0.3350 & 0.2240 & 0.1170 & 0.7074 & 0.0449 \\
\hline DJIM/WTI & -0.0093 & 0.1214 & 0.6219 & -0.2821 & 0.2101 & 0.1089 & 0.6810 & 0.0401 \\
\hline DJIBSC/WTI & 0.1006 & 0.1520 & 0.9770 & -0.1790 & 0.2879 & 0.1706 & 0.9800 & 0.0444 \\
\hline DJICYC/WTI & 0.0131 & 0.1489 & 0.8128 & -0.3036 & 0.2201 & 0.0952 & 0.6099 & 0.0345 \\
\hline DJINCY/WTI & -0.0510 & 0.0856 & 0.5700 & -0.3035 & 0.1691 & 0.0902 & 0.6515 & 0.0279 \\
\hline DJIENE/WTI & 0.1169 & 0.1529 & 0.8685 & -0.2323 & 0.2969 & 0.1498 & 0.9201 & 0.0534 \\
\hline DJIFIN/WTI & 0.0903 & 0.2192 & 0.9944 & -0.2981 & 0.2671 & 0.1485 & 0.9933 & 0.0386 \\
\hline DJIHCR/WTI & -0.0208 & 0.1247 & 0.7789 & -0.2945 & 0.1921 & 0.0877 & 0.6330 & 0.0376 \\
\hline DJIIDU/WTI & 0.0125 & 0.1288 & 0.6726 & -0.2851 & 0.2280 & 0.1225 & 0.7521 & 0.0436 \\
\hline DJITEC/WTI & 0.1371 & 0.2527 & 0.9360 & -0.2864 & 0.2910 & 0.1225 & 0.8299 & 0.0442 \\
\hline DJITLS/WTI & 0.0229 & 0.1646 & 0.7351 & -0.2964 & 0.2249 & 0.0095 & 0.6172 & 0.0454 \\
\hline DJIUTI/WTI & -0.0126 & 0.1243 & 0.9574 & -0.3037 & 0.2098 & 0.1104 & 0.8959 & 0.0399 \\
\hline
\end{tabular}

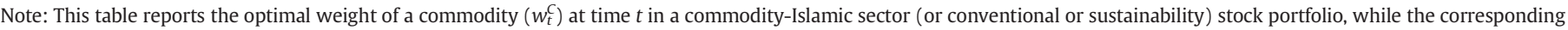

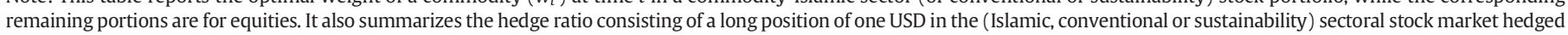
by a short position of $\beta$ USD in the commodity market. 

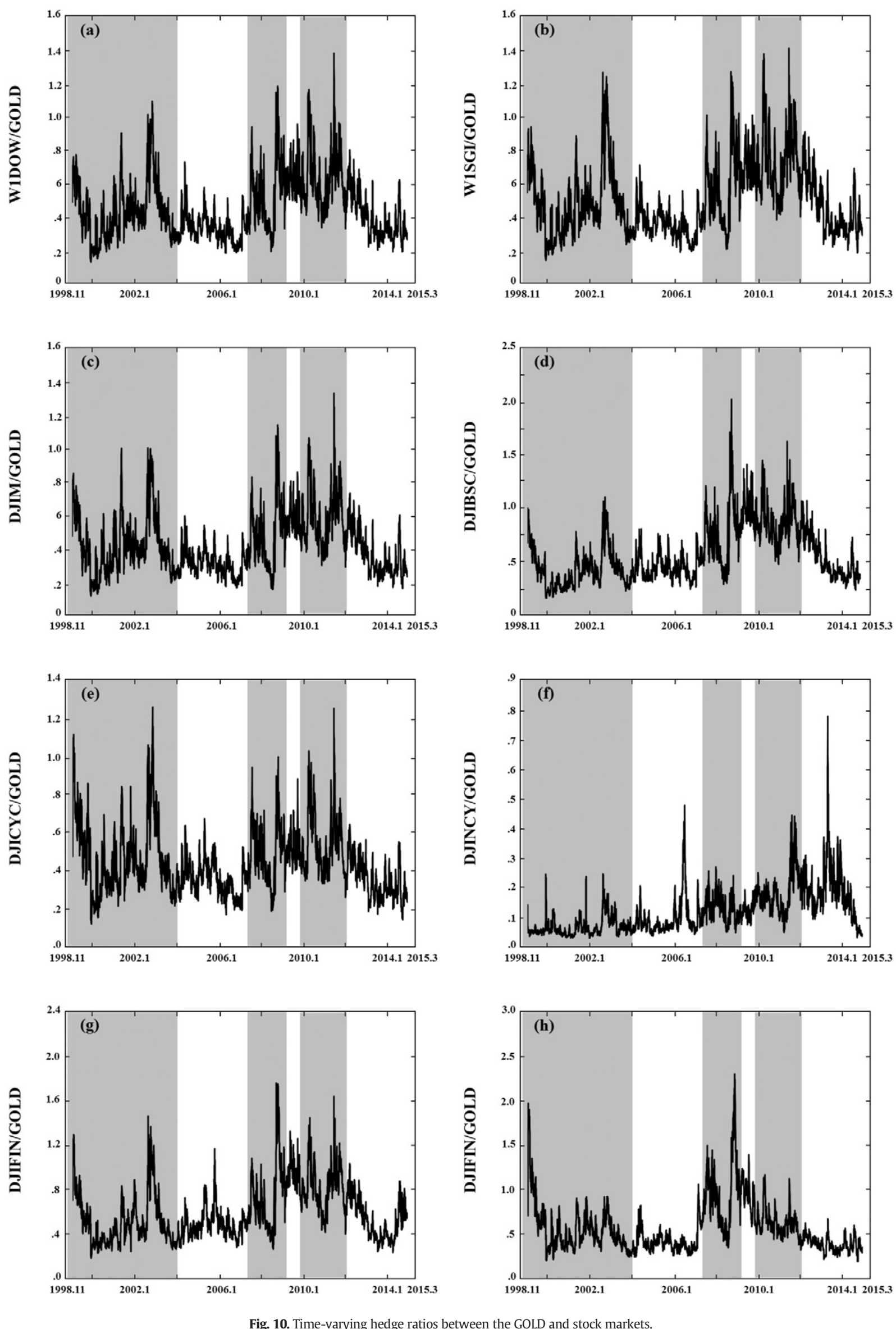

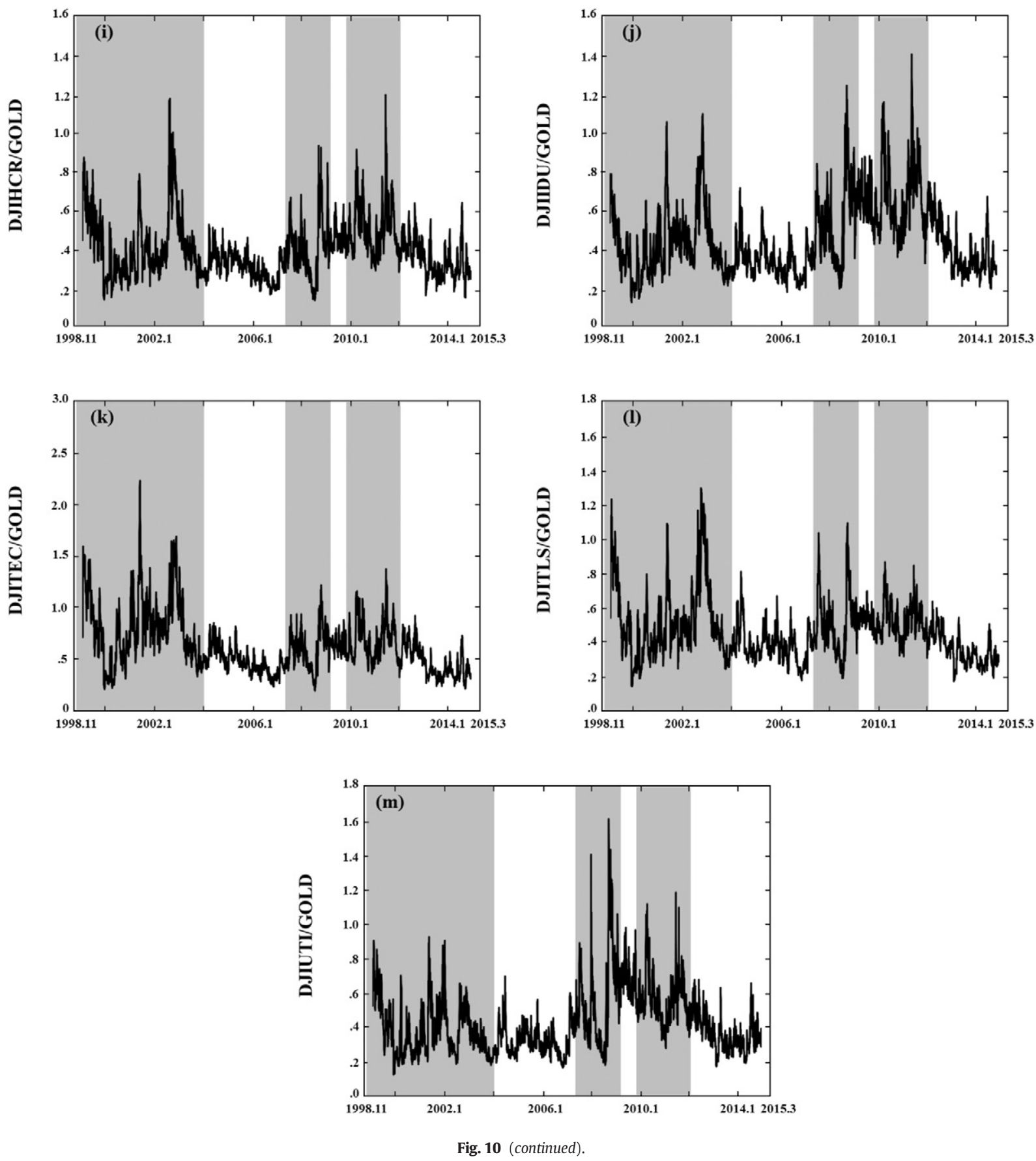

More precisely, the volatility spillovers attain their maximum level during the turbulent years 2008-2009 and 2010-2012, which correspond to the GFC and ESDC periods. In addition, we can conclude that the time-varying volatility spillovers can be affected by other major economic events like the high oil price instability in summer 2008 and January 2014, the 2003 gulf war and the 2007-2008 commodity crisis. These major events increase the spillovers between these markets, and thereby decrease the investment diversification opportunities.

\subsection{Net volatility spillover and robustness tests}

We deepen our study by determining the directional volatility spillovers among the conventional, sustainability, Islamic sector and commodity markets. In fact, we determine the net receivers and net contributors to volatility spillovers. Specifically, we decompose the total volatility spillover index into two directional spillovers as illustrated in Table 5: (i) the receiver of volatility spillovers, termed directionally as 'from', and (ii) the transmitter of volatility spillovers, termed directionally as 'to'. The dynamic net volatility spillover index is then quantified by subtracting directional 'to' spillovers from directional 'from' spillovers. Then positive (negative) values indicate a source (recipient) of return and volatility to (from) others. The results (shown in Table 5) indicate that oil and gold are net receivers of volatility, while the conventional index, the sustainability index and the DJIM index are net contributors to volatility spillovers. Regarding the Islamic sectors, five out of the ten sectors are net contributors to volatility. These sectors are the consumer services, consumer goods, health care, industrials and utilities sectors. The remaining sectors are net receivers of volatility. Among the ten sectors, the highly cyclical industrial sector is the most contributor of risk to the other markets, while the financial 
Table 7

Risk evaluation for the different GOLD-stock portfolios.

\begin{tabular}{|c|c|c|c|c|}
\hline & & Portfolio II & Portfolio III & Portfolio IV \\
\hline \multirow[t]{4}{*}{ W1D0W } & RiskRed. & 0.98733 & 0.51436 & 0.93144 \\
\hline & VaRRed. & 0.02508 & 0.01869 & 0.01155 \\
\hline & SV Red. & 0.25440 & 0.00048 & 0.00641 \\
\hline & ReRed. & 0.05070 & 0.00721 & 0.02535 \\
\hline \multirow[t]{4}{*}{ W1SGI } & RiskRed. & 0.95483 & 0.69804 & 0.89216 \\
\hline & VaRRed. & 0.02065 & 0.01770 & 0.01992 \\
\hline & SV Red. & 0.09759 & 0.00456 & 0.04287 \\
\hline & ReRed. & 0.03128 & 0.00709 & 0.02082 \\
\hline \multirow[t]{4}{*}{ DJIM } & RiskRed. & 0.97418 & 0.39922 & 0.92898 \\
\hline & VaRRed. & 0.01574 & 0.01278 & 0.01549 \\
\hline & SV Red. & 0.01831 & 0.00045 & 0.00705 \\
\hline & ReRed. & 0.04274 & 0.00669 & 0.02660 \\
\hline \multirow[t]{4}{*}{ DJIBSC } & RiskRed. & 0.97721 & 0.03202 & 0.98293 \\
\hline & VaRRed. & 0.00541 & 0.01279 & 0.02263 \\
\hline & SV Red. & 0.09043 & 0.01652 & 0.03280 \\
\hline & ReRed. & 0.04694 & 0.00833 & 0.04909 \\
\hline \multirow[t]{4}{*}{ DJICYC } & RiskRed. & 0.97416 & 0.38721 & 0.96517 \\
\hline & VaRRed. & 0.00688 & 0.01328 & 0.01746 \\
\hline & SV Red. & 0.01591 & 0.00045 & 0.01304 \\
\hline & ReRed. & 0.03995 & 0.00670 & 0.03612 \\
\hline \multirow[t]{4}{*}{ DJINCY } & RiskRed. & 0.98011 & 0.62005 & 0.53293 \\
\hline & VaRRed. & 0.00934 & 0.01353 & 0.01057 \\
\hline & SV Red. & 0.08520 & 0.00028 & 0.01217 \\
\hline & ReRed. & 0.02933 & 0.00528 & 0.01103 \\
\hline \multirow[t]{4}{*}{ DJIENE } & RiskRed. & 0.98283 & 0.17965 & 0.99526 \\
\hline & VaRRed. & 0.01082 & 0.01377 & 0.01869 \\
\hline & SV Red. & 0.02843 & 0.00087 & 0.04504 \\
\hline & ReRed. & 0.05334 & 0.00944 & 0.07252 \\
\hline \multirow[t]{4}{*}{ DJIFIN } & RiskRed. & 0.92924 & 0.18388 & 0.95941 \\
\hline & VaRRed. & 0.01082 & 0.01107 & 0.01303 \\
\hline & SV Red. & 0.06983 & 0.00056 & 0.05263 \\
\hline & ReRed. & 0.02645 & 0.00748 & 0.02379 \\
\hline \multirow[t]{4}{*}{ DJIHCR } & RiskRed. & 0.98662 & 0.48202 & 0.73273 \\
\hline & VaRRed. & 0.00737 & 0.01377 & 0.01770 \\
\hline & SV Red. & 0.29729 & 0.00039 & 0.11322 \\
\hline & ReRed. & 0.06491 & 0.00944 & 0.03713 \\
\hline \multirow[t]{4}{*}{ DJIIDU } & RiskRed. & 0.95513 & 0.38058 & 0.88437 \\
\hline & VaRRed. & 0.01008 & 0.01328 & 0.01598 \\
\hline & SV Red. & 0.09236 & 0.00048 & 0.04839 \\
\hline & ReRed. & 0.03042 & 0.00690 & 0.21956 \\
\hline \multirow[t]{4}{*}{ DJITEC } & RiskRed. & 0.97291 & 0.50729 & 0.99600 \\
\hline & VaRRed. & 0.01229 & 0.01180 & 0.01377 \\
\hline & SV Red. & 0.18212 & 0.01051 & 0.37358 \\
\hline & ReRed. & 0.04272 & 0.01050 & 0.06922 \\
\hline \multirow[t]{4}{*}{ DJITLS } & RiskRed. & 0.97676 & 0.62733 & 0.99314 \\
\hline & VaRRed. & 0.01082 & 0.01057 & 0.01451 \\
\hline & SV Red. & 0.18215 & 0.00056 & 0.21135 \\
\hline & ReRed. & 0.04283 & 0.00751 & 0.04629 \\
\hline \multirow[t]{4}{*}{ DJIUTI } & RiskRed. & 0.98362 & 0.33088 & 0.98843 \\
\hline & VaRRed. & 0.00590 & 0.01352 & 0.00418 \\
\hline & SV Red. & 0.23549 & 0.00047 & 0.39498 \\
\hline & ReRed. & 0.04855 & 0.00692 & 0.03847 \\
\hline
\end{tabular}

Notes: This table reports the results of risk evaluation for portfolios composed of commodity and stocks, compared to a pure Islamic stock portfolio. Portfolio II and IV's weights are given by Eqs. (14) and (15), respectively. On the other hand, Portfolio III has equal weights. "Risk Red." indicates the risk effectiveness ratio in Eq. (16). "VaR. Red." is the reduction in the value-at-risk portfolio with respect to Portfolio I (positive values indicate a VaR reduction). Similarly, "SV Red." and "Re Red." indicate the reduction using the Semivariance and Regret risk measures, respectively. The bold values refer to the portfolio that has the best risk reduction among the three portfolios for each of the commodity-Islamic stock pairs.

sector is the most receiver of risk from the other markets. Financial sectors are marked by their volatility. For the two commodities, oil is a more receiver of shocks than gold is, which is significantly used in central banks' international reserves and is a store of value. Oil is a cyclical commodity, while gold is a safe haven.

The graphical evidence shown in Fig. 8 confirms the results of Tables $4-5$. The figure plots the time-variations of the net volatility spillover index for each Islamic stock sector, the conventional index, the sustainability index, gold and oil, and highlights that
Table 8

Risk evaluations for different WTI-stock portfolios.

\begin{tabular}{|c|c|c|c|c|}
\hline & & Portfolio II & Portfolio III & Portfolio IV \\
\hline \multirow[t]{4}{*}{ W1D0W } & RiskRed. & 0.87829 & 0.21279 & 0.79561 \\
\hline & VaRRed. & 0.01254 & 0.01770 & 0.02065 \\
\hline & SV Red. & 0.13703 & 0.00598 & 0.03566 \\
\hline & ReRed. & 0.03713 & 0.00774 & 0.01893 \\
\hline \multirow[t]{4}{*}{ W1SGI } & RiskRed. & 0.98989 & 0.76921 & 0.73732 \\
\hline & VaRRed. & 0.01352 & 0.01820 & 0.02065 \\
\hline & SV Red. & 0.13332 & 0.00067 & 0.00909 \\
\hline & ReRed. & 0.11509 & 0.00818 & 0.02996 \\
\hline \multirow[t]{4}{*}{ DJIM } & RiskRed. & 0.99729 & 0.79209 & 0.59349 \\
\hline & VaRRed. & 0.02336 & 0.01278 & 0.01328 \\
\hline & SV Red. & 0.01191 & 0.00063 & 0.00619 \\
\hline & ReRed. & 0.38625 & 0.00794 & 0.02487 \\
\hline \multirow[t]{4}{*}{ DJIBSC } & RiskRed. & 0.99818 & 0.65232 & 0.93166 \\
\hline & VaRRed. & 0.06271 & 0.01352 & 0.01672 \\
\hline & SV Red. & 0.07387 & 0.00098 & 0.00222 \\
\hline & ReRed. & 0.15132 & 0.00820 & 0.02668 \\
\hline \multirow[t]{4}{*}{ DJICYC } & RiskRed. & 0.99319 & 0.77917 & 0.62547 \\
\hline & VaRRed. & 0.01155 & 0.01180 & 0.01401 \\
\hline & SV Red. & 0.02279 & 0.00067 & 0.00705 \\
\hline & ReRed. & 0.02874 & 0.01318 & 0.01992 \\
\hline \multirow[t]{4}{*}{ DJINCY } & RiskRed. & 0.98630 & 0.87632 & 0.95302 \\
\hline & VaRRed. & 0.00737 & 0.01278 & 0.01254 \\
\hline & SV Red. & 0.07643 & 0.00037 & 0.06418 \\
\hline & ReRed. & 0.08769 & 0.00607 & 0.08015 \\
\hline \multirow[t]{4}{*}{ DJIENE } & RiskRed. & 0.99587 & 0.59769 & 0.85106 \\
\hline & VaRRed. & 0.01746 & 0.01426 & 0.01377 \\
\hline & SV Red. & 0.03581 & 0.00012 & 0.00142 \\
\hline & ReRed. & 0.25094 & 0.01097 & 0.03252 \\
\hline \multirow[t]{4}{*}{ DJIFIN } & RiskRed. & 0.98931 & 0.61079 & 0.89322 \\
\hline & VaRRed. & 0.01451 & 0.00909 & 0.01155 \\
\hline & SV Red. & 0.01557 & 0.00094 & 0.00128 \\
\hline & ReRed. & 0.12517 & 0.00973 & 0.03595 \\
\hline \multirow[t]{4}{*}{ DJIHCR } & RiskRed. & 0.99325 & 0.83483 & 0.50718 \\
\hline & VaRRed. & 0.01205 & 0.01451 & 0.01254 \\
\hline & SV Red. & 0.01648 & 0.00051 & 0.00548 \\
\hline & ReRed. & 0.12892 & 0.00714 & 0.02340 \\
\hline \multirow[t]{4}{*}{ DJIIDU } & RiskRed. & 0.99154 & 0.76165 & 0.66965 \\
\hline & VaRRed. & 0.01426 & 0.01278 & 0.01180 \\
\hline & SV Red. & 0.01767 & 0.00073 & 0.00736 \\
\hline & ReRed. & 0.13408 & 0.00855 & 0.02726 \\
\hline \multirow[t]{4}{*}{ DJITEC } & RiskRed. & 0.99507 & 0.51553 & 0.83061 \\
\hline & VaRRed. & 0.01893 & 0.01205 & 0.01057 \\
\hline & SV Red. & 0.03274 & 0.00147 & 0.01377 \\
\hline & ReRed. & 0.18105 & 0.01213 & 0.03727 \\
\hline \multirow[t]{4}{*}{ DJITLS } & RiskRed. & 0.99250 & 0.75502 & 0.58973 \\
\hline & VaRRed. & 0.01033 & 0.01082 & 0.00983 \\
\hline & SV Red. & 0.02024 & 0.00073 & 0.00622 \\
\hline & ReRed. & 0.14139 & 0.00850 & 0.02491 \\
\hline \multirow[t]{4}{*}{ DJIUTI } & RiskRed. & 0.99400 & 0.77519 & 0.81151 \\
\hline & VaRRed. & 0.00811 & 0.01352 & 0.01598 \\
\hline & SV Red. & 0.20121 & 0.00006 & 0.00904 \\
\hline & ReRed. & 0.14317 & 0.00779 & 0.03009 \\
\hline
\end{tabular}

Notes: see the notes of Table 7. Numbers in bold indicate the best portfolio performance.

the magnitude of volatility spillovers has often changed during the GFC.

To do the robustness analysis, we have conducted two tests to check the sensitivity of the spillover results. First, we check the choice of the order of the VAR. For this purpose, we compute the spillover index for orders 2 to 6 and plot the minimum, maximum, and the median values in Fig. 9(a). Second, we plot the spillover index for the forecast horizons varying from 5 to 10 days in Fig. 9(b). These figures show that the spillover indexes appear to follow similar patterns whatever the choice of the order of the VAR or the choice of the forecast horizon, suggesting that the total spillover plot is not sensitive to the choice of the order of the VAR or the choice of the forecast horizon. Similar alternative values as robustness tests are also adopted by previous studies in the literature (Diebold and Yilmaz, 2009, 2012, 2014; Chau and Deesomsak, 2014; Antonakakis and Kizys, 2015 among others). 


\subsection{Portfolio risk implications}

The empirical evidence reported above has important implications in terms of asset allocations and portfolio risk management. To help individual and institutional investors make more informed decisions, we thus analyze the usefulness of the oil and gold commodity markets in constructing better portfolios. Specifically, we follow Mensi et al. (2015a) to investigate the usefulness of these commodity markets in having better portfolio risk management of the conventional index, the sustainability index and the Islamic stock sectoral markets. We compare the risks for three different portfolios with that of a benchmark portfolio (Portfolio I) composed exclusively of the stock indexes in this case. We could thus assess the potential reduction in the portfolio risk generated by the inclusion of commodities in a more diversified portfolio.

First, we consider the risk-minimizing commodity-stock (sector) portfolio (Portfolio II) without reducing the expected return. According to Kroner and $\mathrm{Ng}$ (1998), at time $t$ the optimal weight of a commodity in this portfolio $\left(w_{t}^{C}\right)$ is given by:

$w_{t}^{C}=\frac{h_{t}^{S}-h_{t}^{C S}}{h_{t}^{C}-2 h_{t}^{C S}+h_{t}^{S}}$, with $w_{t}^{C}=\left\{\begin{array}{ll}0 & w_{t}^{C}<0 \\ w_{t}^{C} & 0 \leq w_{t}^{C} \leq 1 \\ 1 & w_{t}^{C}>1\end{array}\right.$,

where $\left(h_{t}^{C}\right),\left(h_{t}^{S}\right)$, and $\left(h_{t}^{C S}\right)$ are the conditional volatility of a commodity market, the conditional volatility of the stock market and the conditional covariance between the commodity and the stock markets at time $t$, respectively. From the budget constraint, the optimal weight of the (conventional or sustainability or Islamic) sector market is equal to $\left(1-w_{t}^{C}\right)$. For each commodity-(conventional, sustainability or Islamic) stock pair, all information needed to compute $w_{t}^{C}$ is obtained from the bivariate DECO-FIAPARCH model with Student-t distributions.

Second, we consider another portfolio where the weights are exogenously determined (Portfolio III), i.e., an equally weighted portfolio, which usually has a good out-of-sample performance (DeMiguel et al., 2009). Finally, we consider a fourth portfolio where the weights are determined according to a variance minimization-hedging strategy (Portfolio IV), consisting of a long position of one USD in the (conventional, sustainability or Islamic) aggregate or sectoral stock market hedged by a short position of $\beta$ USD in the commodity market, where $\beta$ at time $t$ is given by:

$\beta_{t}=\frac{h_{t}^{C S}}{h_{t}^{C}}$,

The risk-reduction effectiveness of each portfolio is evaluated by comparing the percentage reduction in the variance of any portfolio with respect to that of Portfolio I, expressed as:

$R E_{\operatorname{Var}}=1-\frac{\operatorname{Var}\left(P_{j}\right)}{\operatorname{Var}\left(P_{I}\right)}$

where $\operatorname{Var}\left(P_{j}\right)$ and $\operatorname{Var}\left(P_{I}\right)$ are the variances of Portfolio $j$ and Portfolio I, respectively, and $j=I I$, III, IV for the portfolios. $R E_{V a r}$ takes values in $[0,1]$, where a higher value indicates a greater variance reduction.

Further, we assess the attractiveness of the commodity markets (oil and gold) in providing downside risk protection, using three different downside risk measures. For each portfolio, we estimate the Value-at-Risk (VaR), the Semivariance (SV) and the Regret (Re). The VaR provides the maximum loss in a portfolio value for a given time period and a given confidence level. ${ }^{7}$

\footnotetext{
7 The reader can refer to Mensi et al. (2015a) for further information on the specification of these risk measures.
}

The downside risk gains are evaluated by considering the downside risk reductions for Portfolios II, III and IV with respect to Portfolio I, using the risk-reduction ratio in Eq. (21) for each downside risk measure.

Table 6 shows the optimal portfolio weights and the hedge ratios for the conventional index, the sustainability index, Islamic sector indices and the commodity futures (oil and gold). Let us take the gold asset first. We find that investors should hold $32.72 \%$ of this yellow metal and $67.28 \%$ of the budget in the DJIM index. For the gold-Islamic sector pairs, the optimal weight for gold varies between $2.86 \%$ for the consumer goods sector and $60.86 \%$ for the energy sector. This result means that for the consumer goods sector the optimal weight of the gold holding in a one-dollar gold stock portfolio should be $2.86 \%$, while the remaining $97.14 \%$ should be invested in the consumer goods. Similar interpretations hold for the other sectors and both conventional and sustainability indexes. On the whole, we conclude that investors should hold more stocks than gold in their portfolios in order to minimize the risk while keeping the expected return unchanged. More interestingly, the net receiver sectors (energy, finance, telecommunication and technology) require more commodity assets than the net contributor sectors.

As for the WTI crude oil, we find that investors should also hold more (Islamic, conventional and sustainability) stocks than oil in their portfolios. By comparing the oil and gold markets, an investor should hold a greater proportion of her wealth in a gold- stock pair than in an oil-stock pair in order to minimize risk. This result is explained by the better diversification benefits bestowed by gold on portfolios, compared to the high instability of the oil market. The value of the hedge ratio is higher when the investor uses gold than oil to do hedging. Taking for example the gold-DJIM pair, a hedge ratio of 0.3986 implies that one USD long in gold should be shorted by about $39.86 \%$ of the DJIM index. Similar interpretations are valid for the other cases.

Fig. 10 displays the dynamic hedge ratios across the gold and stock markets. The paths suggest a variability is in order for the estimated hedge ratio. In fact, we observe significant time-varying hedge ratios over the sample data, suggesting a dissimilarity between the Islamic sectors, conventional and sustainability indexes and also a switching behavior of investors toward risk. Therefore, investors adjust their portfolio structure and hedging positions frequently according to the (Islamic, conventional and sustainability) stock and commodity market conditions (bear, normal and bull markets).

To deepen our analysis, we assess the risk and downside riskreductions of the different pairs. The risk evaluation results for the goldstock and the oil-stock pairs at the $99 \%$ confidence level are presented in Tables 7-8. Viewing Table 7, the optimally weighted Portfolio II offers the best risk reduction and the largest downside risk reduction for the conventional index, the sustainability index, the DJIM index, and the consumer services, consumer goods, health care and industrials sectors. For the remaining sectors, Portfolio IV provides the best performance in terms of risk reduction, VaR reduction, semivariance and regret reduction. It is worth noting that among the ten Islamic sectors, the best risk reductions are detected for the technology sector, followed by the energy and industrials sectors. The highest risk reduction is for the basic material-gold pairs followed by the energy-gold and the consumer services-gold pairs. These results indicate that including gold in the Islamic stock portfolios helps investors to manage effectively their portfolios.

For the oil market (see Table 8), we find that for all cases the optimally weighted Portfolio II offers the best risk reduction and the largest downside risk reduction than the other competing portfolios (i.e., Portfolio II and Portfolio III). Among the Islamic stock sectors, we show that the basic materials, energy and technology sectors present higher risk reductions and VaR reductions than the remaining sectors. This result shows that investors attain the highest risk reductions by including oil in the stock portfolio. 


\section{Conclusion}

International stock markets and major commodities (particularly gold and oil) have recently become more integrated due to the financialization of commodity markets and the globalization of financial markets. These developments in the world's asset markets have made hedging more difficult, and thereby reducing the benefits from diversification. On the other hand, understanding the risk spillovers between the major commodities (oil and gold) and the behaviors of new business models such the Islamic stock markets (particularly at the sectoral level) is of great importance for the purpose of asset allocation and portfolio risk management.

The aim of this paper is to examine the risk spillovers between the two major commodity markets, crude oil and gold, and both the aggregate Dow Jones Islamic index and its associated ten stock sectors, using the dynamic equicorrelation models and the Diebold and Yilmaz (2012) index. For comparison purposes, we consider the aggregate conventional and sustainability indexes. The current study is conducted on daily data over the period November 9, 1998 through March 5, 2015, which includes several major financial crises that are accused of increasing correlations and causing portfolio re-balances. It also evaluates four portfolios in terms of risk reduction and downside risk reduction, using the risk measures VaR, semivariance and regret tools.

Our results find a dynamic equicorrelation between all the commodity and Islamic markets under consideration, as explained earlier. Moreover, the equicorrelation increases during the 2008-2009 global financial crisis period. Using the DY index, we show timevarying risk spillovers between oil, gold and the aggregate and the associated ten Islamic sectoral stock indexes. More interestingly, the results reveal that both the oil and gold markets and the Islamic energy, financial, technology and telecommunications sectors are net receivers of risk spillovers, while the DJIM index, consumer goods, consumer services, health care, industrials, utilities sectors are net contributors to risk spillovers. The basic materials sector is found to be risk spillover-neutral.

Using the downside risk reduction measures the VaR, semivariance and regret measures, we find that the optimally weighted portfolio offers the best risk reduction and the largest downside risk reduction for all the oil-Islamic sector pairs, the gold-DJIM, the gold-Islamic consumer services, the gold-Islamic consumer goods, the gold-Islamic health care and the gold-Islamic industrials sector. For the rest of the gold-Islamic sector pairs, the hedged portfolio provides the best risk reduction.

Additionally, gold offers better diversification benefits, risk reductions and downside risk reductions than oil. Based on this result, we can recommend gold as a better diversifier and risk reducer than oil. This finding may fit well with many of the wealthy faithful individual and institutional investors who reside in major oil-producing countries whose economies and stock markets are propelled by oil revenues. Further, the Islamic equity sectors show an increasing financial integration with the commodity markets. But these sectors do not respond in similar ways to the commodity price shocks. The basic materials, energy, financial, telecommunications and technology sectors are net risk receivers of spillovers, while the rest of sectors are net risk contributors.

Investors can consider commodity prices to predict the sector equity prices. More interestingly, investors can have the opportunity to allocate their portfolio in distinctive sectors. Finally, gold is helpful for investors dealing with the technology sector, while those investing in the basic materials sector can include oil in their portfolios for risk-reduction purposes. Finally, the Sharia-compliance rules are not restrictive enough to make the Islamic stock equity market very different from the conventional indexes and immune against commodity price shocks.

The results have important implications for investors and portfolio managers. Investing in gold as a complement to Islamic sector investments offers a better way for the investor to diversify their portfolio when their expectations are heterogeneous in terms of risk tolerance and time preference.

It will be intriguing in the future to extend this work by considering the impact of oil and gold on Islamic sector stock market liquidity in the short, medium and long runs.

\section{Acknowledgment}

The last author (Sang Hoon Kang) acknowledges receiving a financial support from the Ministry of Education of the Republic of Korea and the National Research Foundation of Korea (NRF-2016S1A5A2A03926111).

\section{Appendix A. Supplementary data}

Supplementary data to this article can be found online at http://dx. doi.org/10.1016/j.eneco.2017.08.031.

\section{References}

Abdullah, A.M., Saiti, B., Masih, M., 2016. The impact of crude oil price on Islamic stock indices of South East Asian countries: evidence from MGARCH-DCC and wavelet approaches. Borsa Istanbul Rev. 16, 219-232.

Aboura, S., Chevallier, J., 2014. Volatility equicorrelation: a cross-market perspective. Econ. Lett. 122, 289-295.

Ahmad, W., Sehgal, S., Bhanumurthy, N.R., 2013. Eurozone crisis and BRIICKS stock markets: contagion or market interdependence? Econ. Model. 33, 209-225.

Aielli, G.P., 2013. Dynamic conditional correlation: on properties and estimation. J. Bus. Econ. Stat. 31, 282-299.

Al-Khazali, O., Lean, H.H., Samet, A., 2014. Do Islamic stock indexes outperform conventional stock indexes? A stochastic dominance approach. Pac. Basin Financ. J. 28, 29-46.

Antonakakis, N., Kizys, R., 2015. Dynamic spillovers between commodity and currency markets. Int. Rev. Financ. Anal. 41, 303-319.

Balcilar, M., Demirer, R., Hammoudeh, S., 2015. Global risk exposures and industry diversification with Shariah-compliant equity sectors. Pac. Basin Financ. J. 35, 499-520.

Baur, D.G., Lucey, B.M., 2010. Is gold a hedge or a safe haven? An analysis of stocks, bonds and gold. Financ. Rev. 45, 217-229.

Baur, D.G., McDermott, T.K., 2010. Is gold a safe haven? International evidence. J. Bank. Financ. 34, 1886-1898.

Beck, S., Demirgüç-Kunt, A., Merrouche, Q., 2013. Islamic vs. conventional banking: business model, efficiency and stability. J. Bank. Financ. 37, 433-447.

Charfeddine, L., Najah, A., Teulon, F., 2016. Socially responsible investing and Islamic funds: new perspectives for portfolio allocation. Res. Int. Bus. Financ. 36, 351-361.

Chau, F., Deesomsak, R., 2014. Does linkage fuel the fire? The transmission of financial stress across the markets. Int. Rev. Financ. Anal. 36, 57-70.

Clements, A., Scott, A., Silvennoien, A., 2014. On the benefits of equicorrelation for portfolio allocation. NCER Working Paper Series No. 99 (http://www.ncer.edu.au/papers/ documents/WP99.pdf).

DeMiguel, V., Garlappi, L., Nogales, F.J., Uppal, R., 2009. A generalized approach to portfolio optimization: improving performance by constraining portfolio norms. Manag. Sci. $55,798-812$.

Dewandaru, G., Masih, R., Ismath Bacha, O., Masih, A.M.M., 2016. The role of Islamic asset classes in the diversified portfolios: mean variance spanning test. Emerg. Mark. Rev. http://dx.doi.org/10.1016/j.ememar.2016.09.002.

Dickey, D., Fuller, W., 1979. Distribution of the estimators for autoregressive time series with a unit root. J. Am. Stat. Assoc. 74, 427-431.

Diebold, F.X., Yilmaz, K., 2009. Measuring financial asset return and volatility spillovers, with application to global equity markets. Econ. J. 119, 158-171.

Diebold, F.X., Yilmaz, K., 2012. Better to give than to receive: predictive directional measurement of volatility spillovers. Int. J. Forecast. 28, 57-66.

Diebold, F.X., Yilmaz, K., 2014. On the network topology of variance decompositions: measuring the connectedness of financial firms. J. Econ. 182, 119-134.

Diebold, F.X., Yilmaz, K., 2016. Trans-Atlantic equity volatility connectedness: U.S. and European financial institutions, 2004-2014. J. Financ. Econ. 14, 81-127.

Dorsman, A., Koch, A., Jager, M., Thibeault, A., 2012. Adding oil to a portfolio of stocks and bonds? Energy Economics and Financial Markets. Springer Berlin Heidelberg, pp. 197-213

Engle, R.F., 1982. Autoregressive conditional heteroskedasticity with estimates of the variance of United Kingdom inflation. Econometrica 50, 987-1007.

Engle, R.F., 2002. Dynamic conditional correlation: a simple class of multivariate generalized autoregressive conditional heteroskedasticity models. J. Bus. Econ. Stat 20, 339-350.

Engle, R.F., Kelly, B., 2012. Dynamic equicorrelation. J. Bus. Econ. Stat. 30, 212-228.

Fiorentini, G., Sentana, E., Calzolari, G., 2003. Maximum likelihood estimation and inference in multivariate conditionally heteroscedastic dynamic regression models with Student-t innovations. J. Bus. Econ. Stat. 21, 532-546.

Forbes, K., Rigobon, R., 2002. No contagion, only interdependence: measuring stock market comovements. J. Financ. 57, 2223-2261. 
Hamilton, J.D., 1988. Rational-expectations econometric analysis of changes in regime: an investigation of the term structure of interest rates. J. Econ. Dyn. Control. 12, 385-423.

Hamilton, J.D., Susmel, R., 1994. Autoregressive conditional heteroscedasticity and changes in regime. J. Econ. 64, 307-333.

Hammoudeh, S., Mensi, W., Reboredo, J.C., Nguyen, D.K., 2014. Dynamic dependence of the global Islamic equity index with global conventional equity market indices and risk factors. Pac. Basin Financ. J. 30, 189-206.

Hayat, R., Kraussl, R., 2011. Risk and return characteristics of Islamic equity funds. Emerg. Mark. Rev. 12, 189-203.

Islamic Financial Services Board, 2016. IFSI Stability Report 2016. Islamic Financial Services Board, Kuala Lumpur, Malaysia.

Jawadi, F., Jawadi, N., Louhichi, W., 2014. Conventional and Islamic stock price performance: an empirical investigation. Int. Econ. 137, 73-87.

Kang, X., 2012. Commodity investments: the missing piece of the portfolio puzzle? https://papers.ssrn.com/sol3/papers.cfm?abstract_id=2153319

Koop, G., Pesaran, H.M., Potter, S., 1996. Impulse response analysis in nonlinear multivariate models. J. Econ. 74, 119-147.

Kroner, K.F., Ng, V.K., 1998. Modeling asymmetric comovements of asset returns. Rev. Financ. Stud. 11, 817-844.

Kwiatkowski, D., Phillips, P.C.B., Schmidt, P., Shim, Y., 1992. Testing the null hypothesis of stationarity against the alternative of a unit root: how sure are we that economic time series are non-stationary? J. Econ. 54, 159-178.

Majdoub, J., Mansour, W., 2014. Islamic equity market integration and volatility spillover between emerging and US stock markets. N. Am. J. Econ. Financ. 29, 452-470.

Majdoub, J., Mansour, W., Jouini, J., 2016. Market integration between conventional and Islamic stock prices. N. Am. J. Econ. Financ. 37, 436-457.

Mensi, W., Hammoudeh, S., Kang, S.H., 2015a. Precious metals, cereal, oil and stock market linkages and portfolio risk management: evidence from Saudi Arabia. Econ. Model. 51, 340-358.

Mensi, W., Hammoudeh, S., Reboredo, J.C., Nguyen, D.K., 2015b. Are Sharia stocks, gold and U.S. Treasury hedges and/or safe havens for the oil-based GCC markets? Emerg. Mark. Rev. 24, 101-121.
Mensi, W., Hammoudeh, S., Sensoy, A., Yoon, S.M., 2016. Analysing dynamic linkages and hedging strategies between Islamic and conventional sector equity indexes. Appl. Econ. http://dx.doi.org/10.1080/00036846.2016.1240349.

Milly, M., Sultan, J., 2012. Portfolio Diversification During Financial Crisis: Analysis of Faith Based Investment Strategies. Building Bridges Across the Financial Communities: The Global Financial Crisis, Social Responsibility, and Faith-based Finance. Harvard Law School, Islamic Finance Project, pp. 334-352.

Nagayev, R., Disli, M., Inghelbrecht, K., Ng, A., 2016. On the dynamic links between commodities and Islamic equity. Energy Econ. 58, 125-140.

Pan, Z., Wang, Y., Liu, L., 2016. The relationship between petroleum and stock returns: an asymmetric dynamic equi-correlation approach. Energy Econ. 56, 453-463.

Pesaran, H.H., Shin, Y., 1998. Generalized impulse response analysis in linear multivariate models. Econ. Lett. 58, 17-29.

Phillips, P.C.B., Perron, P., 1988. Testing for unit roots in time series regression. Biometrika 75, 335-346

Rahim, A.M., Masih, M., 2016. Portfolio diversification benefits of Islamic investors with their major trading partners: evidence from Malaysia based on MGARCH-DCC and wavelet approaches. Econ. Model. 54, 425-438.

Saiti, B., Bacha, O.I., Masih, M., 2014. The diversification benefits from Islamic investment during the financial turmoil: the case for the US-based equity investors. Borsa Istanbul Rev. 14, 196-211.

Sensoy, A., 2016. Systematic risk in conventional and Islamic equity markets. Int. Rev. Financ. 16, 457-466.

Silvennoinen, A., Thorp, S., 2013. Financialization, crisis and commodity correlation dynamics. J. Int. Financ. Mark. Inst. Money 24, 42-65.

Tse, Y.K., 1998. The conditional heteroscedasticity of the Yen-Dollar exchange rate. J. Appl. Econ. 13, 49-55.

Umar, Z., 2017. Islamic vs conventional equities in a strategic asset allocation framework. Pac. Basin Financ. J. 42, 1-10.

Yilmaz, M.K., Sensoy, A., Ozturk, K., Hacihasanoglu, E., 2015. Cross-sectoral interactions in Islamic equity markets. Pac. Basin Financ. J. 32, 1-20. 